\title{
Earthquake faulting in subduction zones: insights from fault rocks in accretionary prisms
}

Kohtaro Ujiie ${ }^{1,2^{*}}$ and Gaku Kimura ${ }^{3}$

\begin{abstract}
Subduction earthquakes on plate-boundary megathrusts accommodate most of the global seismic moment release, frequently resulting in devastating damage by ground shaking and tsunamis. As many earthquakes occur in deep-sea regions, the dynamics of earthquake faulting in subduction zones is poorly understood. However, the Integrated Ocean Drilling Program (IODP) Nankai Trough Seismogenic Zone Experiment (NanTroSEIZE) and fault rock studies in accretionary prisms exhumed from source depths of subduction earthquakes have greatly improved our understanding of earthquake faulting in subduction zones. Here, we review key advances that have been made over the last decade in the studies of fault rocks and in laboratory experiments using fault zone materials, with a particular focus on the Nankai Trough subduction zone and its on-land analog, the Shimanto accretionary complex in Japan. New insights into earthquake faulting in subduction zones are summarized in terms of the following:

(1) the occurrence of seismic slip along velocity-strengthening materials both at shallow and deep depths;

(2) dynamic weakening of faults by melt lubrication and fluidization, and possible factors controlling coseismic deformation mechanisms; (3) fluid-rock interactions and mineralogical and geochemical changes during earthquakes; and (4) geological and experimental aspects of slow earthquakes.
\end{abstract}

Keywords: Subduction earthquake; Accretionary prism; Fault rock; NanTroSEIZE

\section{Review}

\section{Introduction}

Great subduction earthquakes $\left(M_{w}>8.0\right)$ commonly occur along plate-boundary thrusts beneath accretionary prisms. Ground shaking and tsunamis generated in association with earthquake faulting in subduction zones inflict a great natural hazard to humans, and yet our understanding of how subduction earthquakes and tsunamis occur remains poor.

Thermal models suggest that subduction earthquakes occur in a temperature range of approximately $100^{\circ} \mathrm{C}$ to $150^{\circ} \mathrm{C}$ to approximately $350^{\circ} \mathrm{C}$ to $450^{\circ} \mathrm{C}$ (Hyndman et al. 1997; Oleskevich et al. 1999). It was proposed that the updip limit of the seismogenic subduction zone may be controlled by diagenetic to low-grade metamorphic processes such as quartz cementation and pressure solution

\footnotetext{
* Correspondence: kujiie@geol.tsukuba.ac.jp

'Graduate School of Life and Environmental Sciences, University of Tsukuba, 1-1-1 Tennodai, Tsukuba 305-0006, Japan

${ }^{2}$ Research and Development Center for Ocean Drilling Science, Japan Agency for Marine-Earth Science and Technology, 2-15 Natsushima-cho, Yokosuka 237-0061, Japan

Full list of author information is available at the end of the article
}

(Moore and Saffer 2001), while the downdip limit could correspond with the onset of plastic deformation or a serpentinized mantle (Hyndman et al. 1997). It was conventionally thought that the shallow portions of the plate-boundary thrusts were aseismic, owing to the velocity-strengthening frictional behavior of unconsolidated materials, while the seismogenic portions of plate boundaries exhibited a velocity-weakening behavior (Marone and Scholz 1988; Moore and Saffer 2001). Vrolijk (1990) proposed that the transformation of smectite to illite may control the updip limit of seismogenic subduction zones because it occurs in the temperature range of $100^{\circ} \mathrm{C}$ to $150^{\circ} \mathrm{C}$. However, both smectite and illite commonly show velocity-strengthening frictional behavior at low slip rates; thus, it is unlikely that the smectite to illite transformation controls the updip limit of the seismogenic zone (Saffer and Marone 2003; Ikari et al. 2007).

The 2011 Tohoku-Oki earthquake $\left(M_{w} 9.0\right)$ has provided an invaluable opportunity to rethink the updip limit of the seismogenic subduction zone. Seafloor global positioning system measurements, repeated bathymetry and seismic 
surveys, and numerous coseismic slip distribution models indicate that the coseismic slip extended all the way to the Japan Trench axis with an unprecedented slip displacement of approximately $50 \mathrm{~m}$ (e.g., Fujiwara et al. 2011; Ide et al. 2011; Sato et al. 2011; Kodaira et al. 2012). The Integrated Ocean Drilling Program (IODP) Expedition 343 and 343 T, Japan Trench Fast Drilling Project (JFAST), successfully detected the residual heat associated with the earthquake on the shallow plate-boundary thrust near the Japan Trench axis (Fulton et al. 2013). Logging while drilling and observations of the recovered cores indicated that the plate-boundary faulting is localized along a pelagic clay layer less than $5 \mathrm{~m}$ thick (Chester et al. 2013). High-velocity friction experiments on the plate-boundary thrust material suggest that the large coseismic slip can be explained by a very low coseismic shear stress, which can be attributed to both the abundance of smectite in the pelagic clay and thermal pressurization effects (Ujiie et al. 2013). Notably, JFAST confirmed that the large coseismic slip occurred in the shallow subduction thrust where earthquakes are unlikely to nucleate.

Seismological and geodetic observations made in the twenty-first century have revealed that seismic and aseismic slips are the end members of various fault slip behaviors. Slow earthquakes in subduction zones, detected by the widespread development of seismic observation networks and GPS stations, can be categorized according to their predominant frequency or period, which comprise low frequency tremors, low frequency and very low frequency earthquakes, and slow slip events (e.g. Obara 2002; Rogers and Dragert 2003; Shelly et al. 2006; Ito and Obara 2006a; Ito et al. 2007). Slow earthquakes reflect transient modes of fault slip with longer characteristic durations, and they radiate much less seismic energy than regular earthquakes (Ide et al. 2007). The spatial distribution of slow earthquakes suggests that transient slip appears to occur in the transition zone between seismic and aseismic slip zones (Ito and Obara 2006a; Ito et al. 2007; Sugioka et al. 2012). Thus, a locked seismogenic zone with aseismic zone above and below is an oversimplified conceptual view.

Concurrently with an increased understanding of the complex modes of fault slip in subduction zones, our understanding of plate-boundary faulting associated with dynamic earthquake rupture and slow earthquakes has progressed. In recent years, active fault drilling has been conducted by the IODP Nankai Trough Seismogenic Zone Experiment (NanTroSEIZE) project, focusing on the Nankai accretionary margin offshore the Kii Peninsula, southwest Japan, where great subduction earthquakes have repeatedly occurred (Figure 1a,b). The coseismic slip distribution of the 1944 Tonankai earthquake $\left(M_{w} 8.1\right)$ inferred from tsunami and seismic waveform inversions suggests that the earthquake rupture propagated along a megasplay fault (or an out-of-sequence thrust) that branches from the plate-boundary megathrust and cuts through the prism (Tanioka and Satake 2001; Kikuchi et al. 2003). The ultimate goals of the NanTroSEIZE deep drilling program are to sample the plate-boundary megathrust and megasplay fault materials at an approximately $6-\mathrm{km}$ depth and to instrument an observatory system across the plate-boundary fault system (Tobin and Kinoshita 2006). Although this complex ocean drilling project is ongoing, fault rocks have been obtained from the shallow portions of the megasplay fault and plateboundary thrust (Figure 1b). Moreover, field studies of exhumed subduction thrusts and out-of-sequence thrusts, microstructural and chemical analyses of fault rocks, and laboratory experiments on fault zone materials have been vigorously conducted over the past decade because fault rocks in exhumed accretionary prisms have provided a window to examine earthquake processes in subduction zones that are not accessible or observable using ocean drilling.

In this review, we summarize and discuss new findings and major progresses that have been made in fault rock studies of accretionary prisms. In particular, we focus on identification of past seismic slips from fault rocks, coseismic deformation mechanisms, physical and chemical processes that occur during earthquake faulting, and the estimation of earthquake source parameters through fault rocks and laboratory experiments. First, we describe the structure of the megasplay fault and active plate-boundary thrust in the Nankai subduction zone and show how shallow earthquake ruptures were recorded in fault gouges. Then, we review earthquake faulting and earthquake- or earthquake cycle-related fluid-rock interactions recorded in various fault rocks in exhumed accretionary complexes with an emphasis on but not limited to research results from the Shimanto accretionary complex in Japan, the onland analog of the Nankai accretionary prism (Figure 1c). We also review progress made in the geological and experimental investigations of slow earthquakes. Finally, we make concluding remarks related to new insights into earthquake faulting in subduction zones.

\section{Fault rocks in the Nankai accretionary prism}

Fault rocks in the shallow portions of the megasplay fault and plate-boundary thrust of the Nankai accretionary prism were collected during IODP NanTroSEIZE Expedition 316 (Figures 2 and 3). In the following subsections, we document primary results of fault rock studies that were obtained during Expedition 316 (Kinoshita et al. 2009) and post-expedition research.

\section{Fault zone structure}

Megasplay fault The shallow portion of the megasplay fault zone was drilled at site C0004 (Figure 1b), where it 


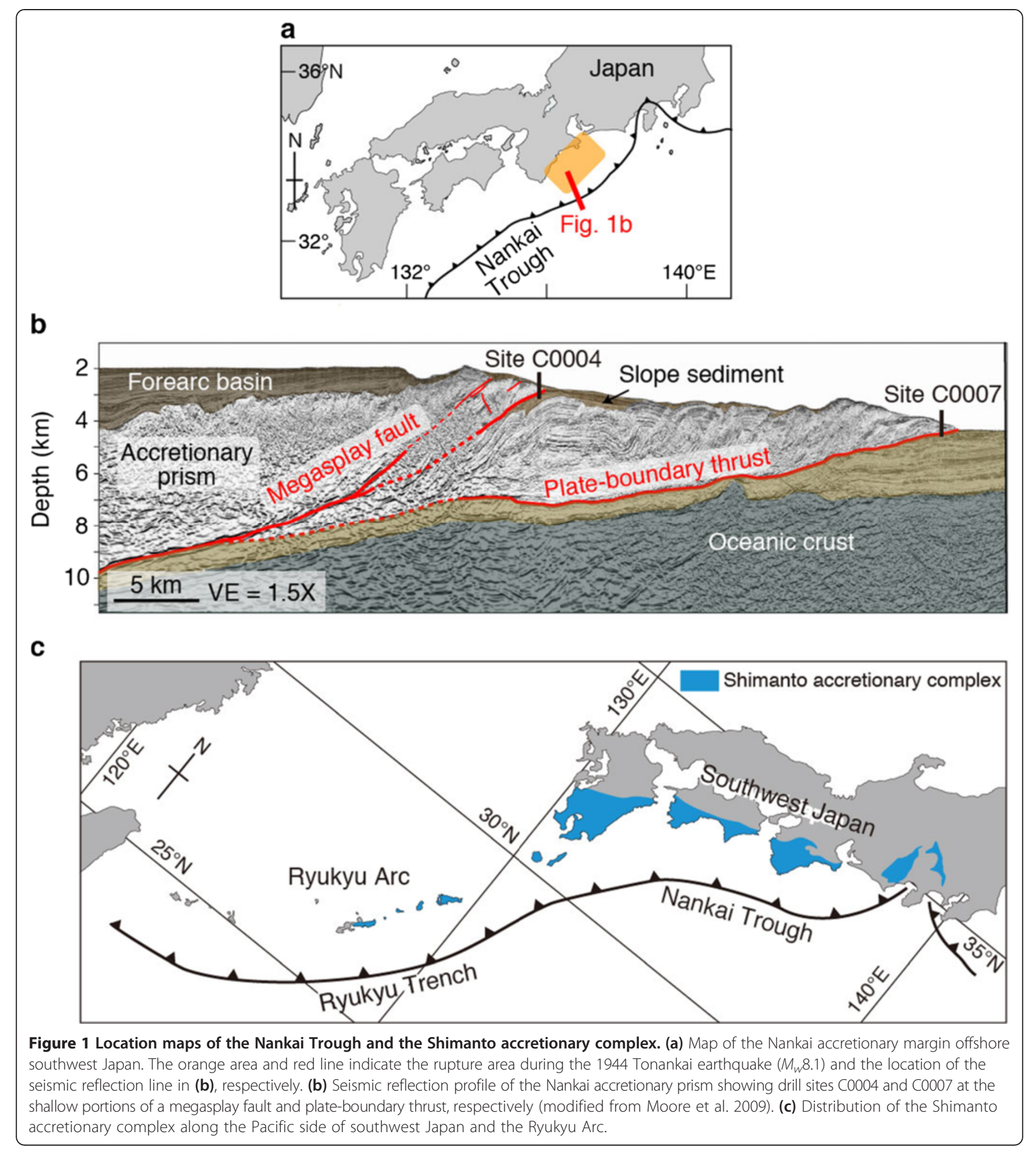

was defined at 256 to $315 \mathrm{~m}$ below the sea floor (mbsf) based on the abrupt occurrence of brecciated fragments with polished and slickenlined surfaces at $256 \mathrm{mbsf}$ and the absence of brecciated and fractured rocks below 315 mbsf. The fault zone is developed in the middle Pliocene hemipelagic mudstone in which volcanic ash layers are frequently distributed (Figure 2). Two biostratigraphic age reversals occur in the fault zone and are consistent with thrust faulting along the megasplay fault. There is no clear evidence of fluid-rock interactions having taken place in the fault zone, such as mineralized veins or alteration.

Structural elements found in the megasplay fault zone include fractured rocks, fault breccia, microbreccia, 


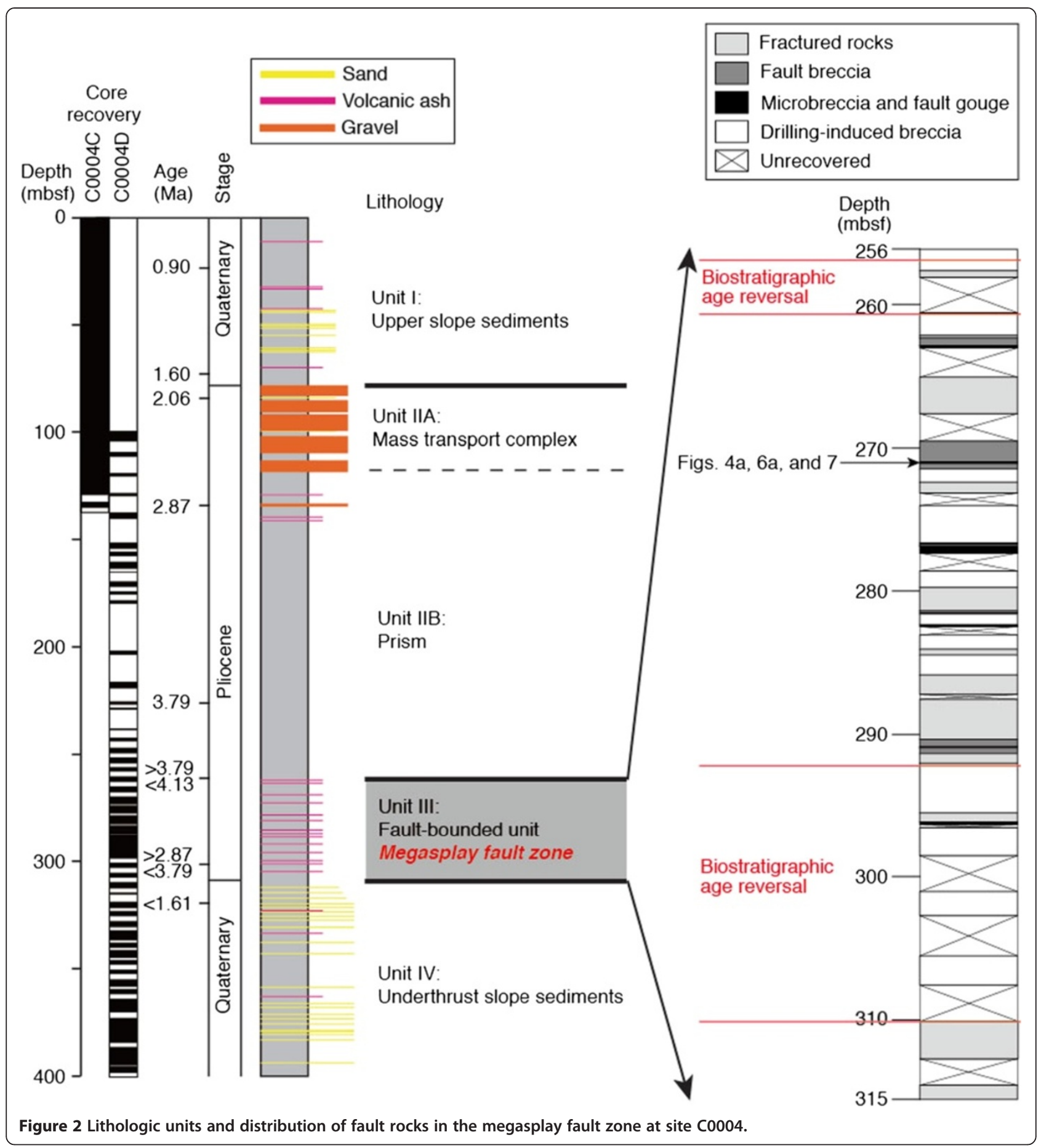

drilling-induced breccia, and fault gouge (Figure 2). Borehole resistivity images obtained from logging while drilling indicate the presence of multiple conductive fractures in the megasplay fault zone, which may inhibit core recovery (Kinoshita et al. 2009). Based on recovered cores, there is a wide distribution of fractured rocks and drilling-induced breccia in the fault zone, while the other abovementioned structural elements show a relatively limited spatial distribution. Fractured rocks are defined by the presence of centimeter- to decimeter-sized trapezoidal broken rock fragments that occur along sets of polished and striated fracture surfaces. Drilling-induced breccia is derived from natural fractured and brecciated rocks that were enhanced by the drilling processes (see Kinoshita et al. 2009 for additional detail about drilling-induced breccia). Fault breccia and microbreccia are characterized by the predominance 


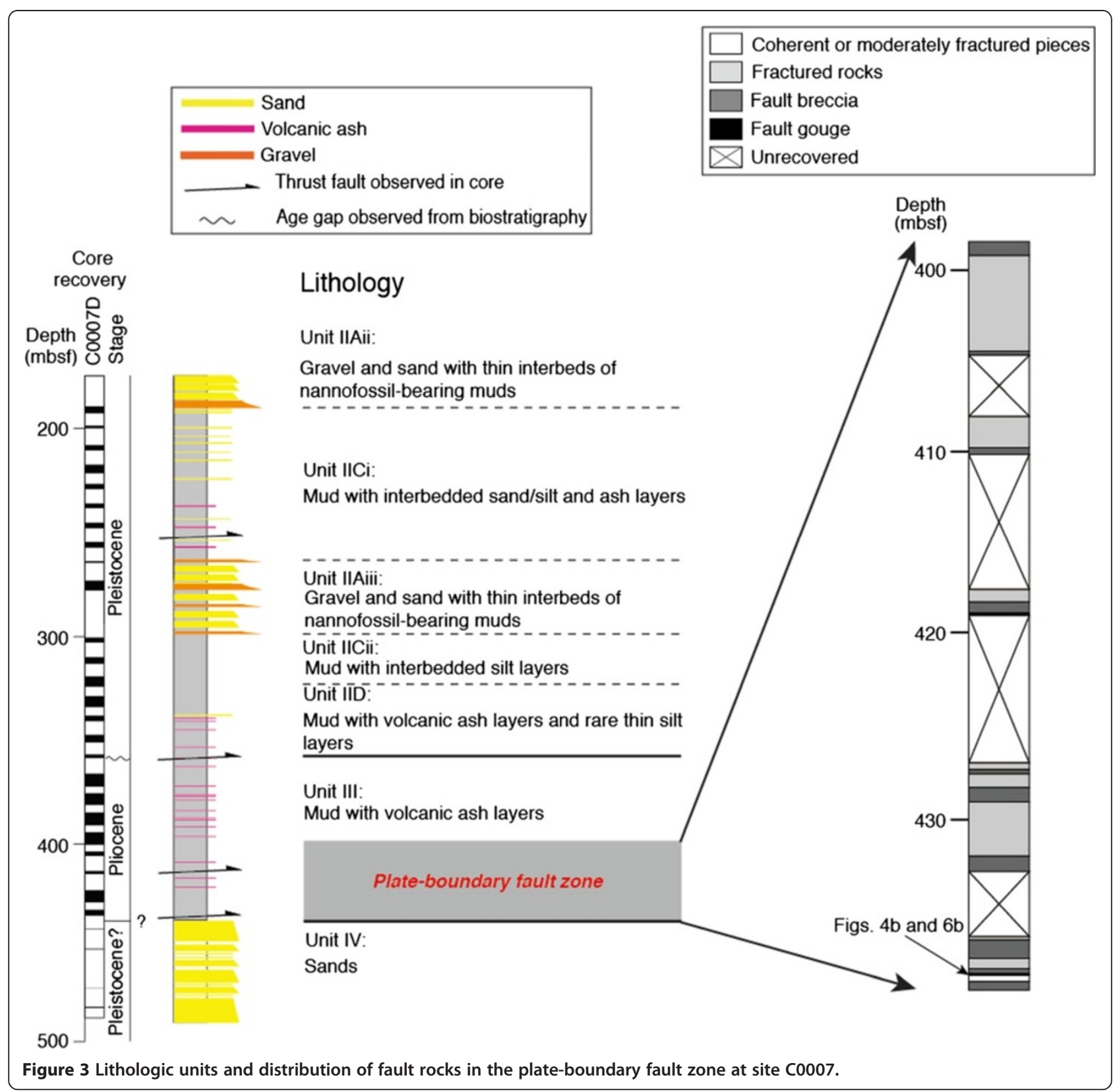

of centimeter- to millimeter-sized and millimeter- to submillimeter-sized, angular to subangular fragments, respectively. Brecciated fragments are commonly polished with variable slip directions. Some fractured rocks and fault breccia show foliations defined by the alignment of fragments along inclined fracture surfaces. Shear displacements along individual fractures and slip surfaces are considered to be small because the original layering of hemipelagic mudstone and ash is mostly preserved despite intense fracturing and brecciation.

Fault gouges develop in microbreccia as approximately 10 -mm-thick dark zones deficient in visible fragments (Figure 4a). At site C0004, one fault gouge smoothly cuts the microbreccia, while the other gouge is undulated and fragmented, indicating the recurrence of microbrecciation and shear localization along the thin gouge zones. On X-ray computed tomography (CT) images, the gouges are expressed as bright zones with relatively high $\mathrm{CT}$ numbers, suggesting that they are denser than the surrounding microbreccia.

Plate-boundary thrust The plate-boundary thrust was drilled at site $\mathrm{C0007}$ (Figure 1b), with the plate-boundary fault zone defined at 398.5 to 446 mbsf based on the spacing of fractures and the preservation of fault breccia and fault gouge. The fault zone and its hanging wall occur in 


\section{a}

\section{Megasplay fault}

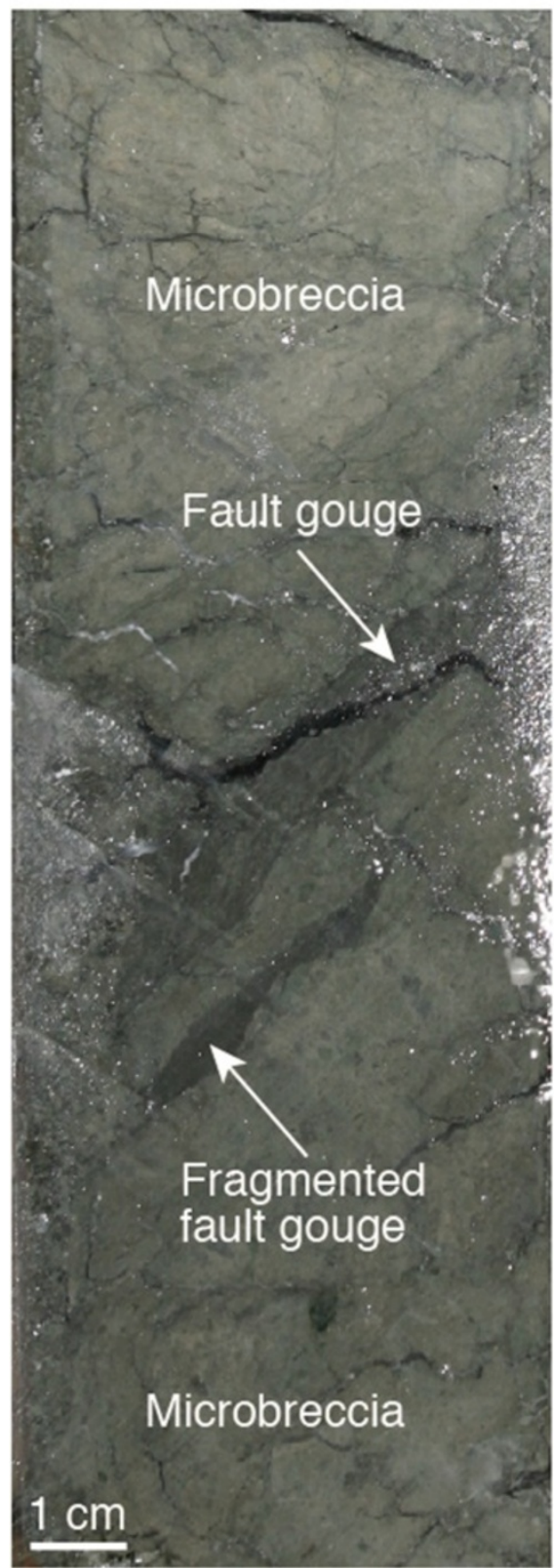

b

Plate-boundary thrust

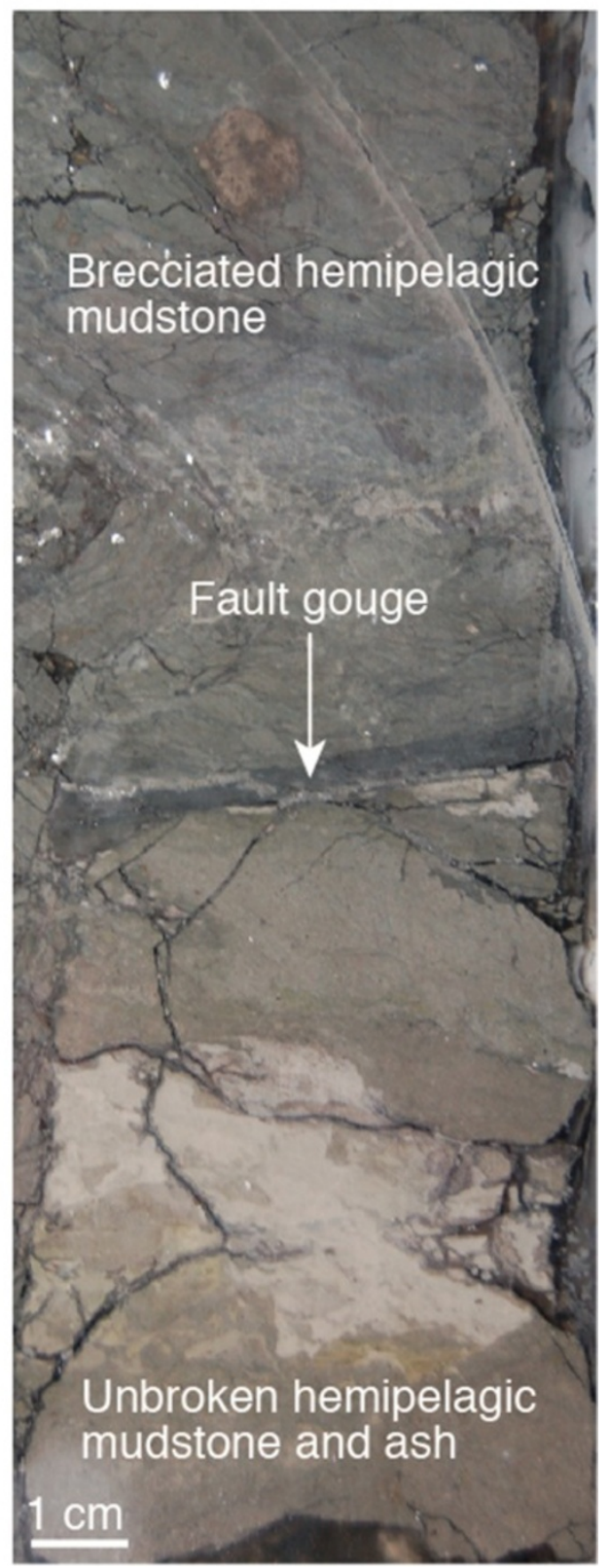

Figure 4 Occurrence of fault gouges in recovered cores. Fault gouges are shown from the (a) megasplay fault zone and (b) plate-boundary fault zone. See Figures 2 and 3 for the locations of fault gouges.

Pliocene hemipelagic mudstone with volcanic ash layers, while the cores recovered from the footwall show sanddominated sediments that are possibly of Pleistocene age, suggesting that temporal and lithological changes are associated with thrust faulting (Figure 3).

The fault zone is characterized by the heterogeneous distribution of fractured and brecciated rocks and a very limited distribution of fault gouges (Figure 3). Fracturing and brecciation in the fault zone show similar characteristics to those in the megasplay fault zone. Microbreccia is absent in the fault zone associated with the plate-boundary thrust.

Fault gouges are developed in two intervals. The fault gouge at 418.83 to 418.94 mbsf shows foliations defined by both the alignment of submillimeter fragments in the clay matrix and color banding. Foliations are cut by the anastomosing slip surfaces that surround fragments. The foliations and slip surfaces locally exhibit a composite 
planar fabric such as a P-Y fabric (Chester and Logan 1987), with the shear sense consistent with thrust faulting. Fault gouges are also found in the lowermost part of the fault zone at 438.28 to $438.57 \mathrm{mbsf}$ where hemipelagic mudstone underwent intense brecciation into approximately 1 - to 10 -mm-sized fragments along an anastomosing network of polished and striated surfaces. The gouges are also intensely brecciated, resulting in fragmentation of gouge or irregular gouge boundaries. However, the 2-mm-thick dark fault gouge at the base of the interval exhibits planar upper and lower boundaries and sharply separates the intensely brecciated hemipelagic mudstone above from the unbroken hemipelagic mudstone and ash below (Figure 4b). A biostratigraphic age reversal that occurs across the interval records an estimated time difference of approximately 1.67 Myr, which suggests that this thin, dark gouge represents an extreme localization of slip during thrust faulting.

\section{Earthquake faulting recorded in fault gouges}

Both the shallow portions of the megasplay fault and the plate-boundary thrust show repeated localization of shear along approximately 2- to 10-mm-thick dark gouges that occur within broader zones undergoing distributed fracture and brecciation (Figure 4). These gouges are marked by the preferred orientation of very fine grained clay particles that are parallel and oblique to gouge boundaries (Figure 5). This contrasts with the surrounding brecciated materials, which show an anastomosing network or relatively widely spaced clay foliations. The relative concentration of clay particles within
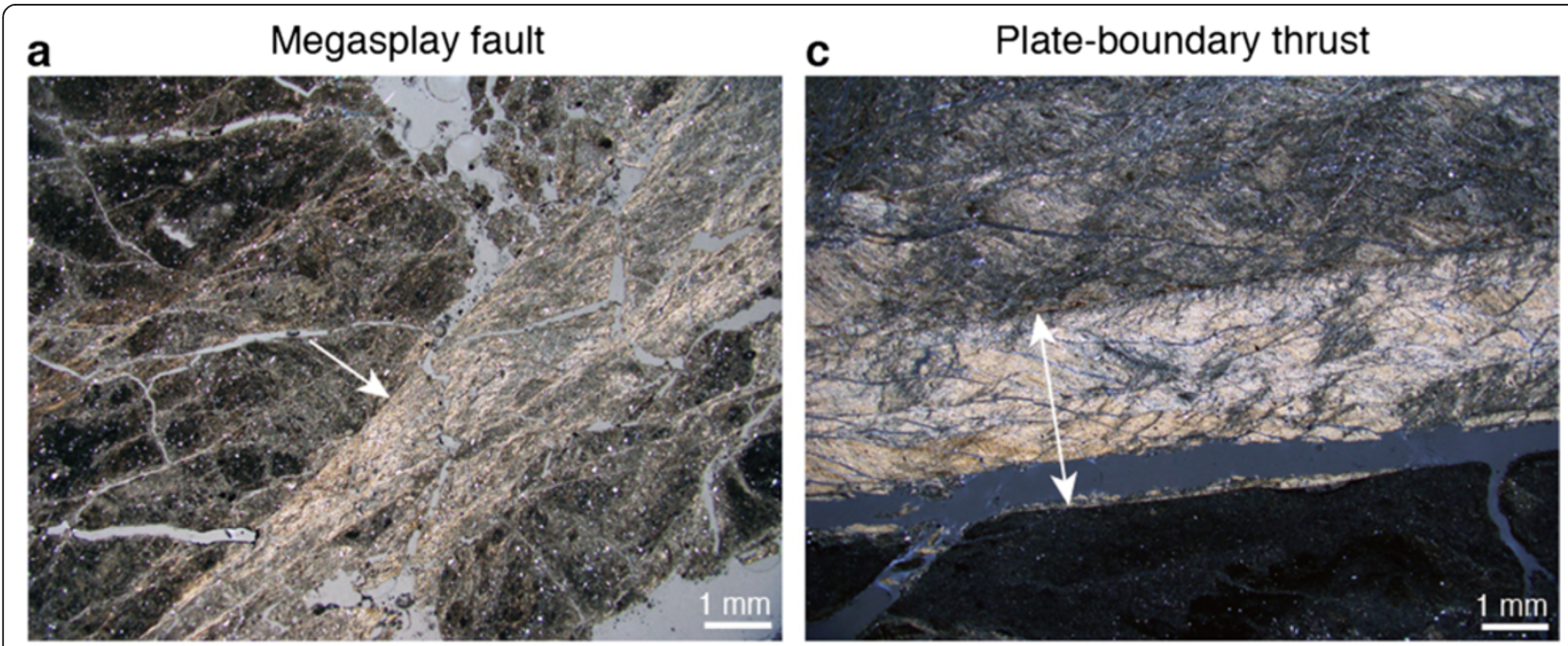

b

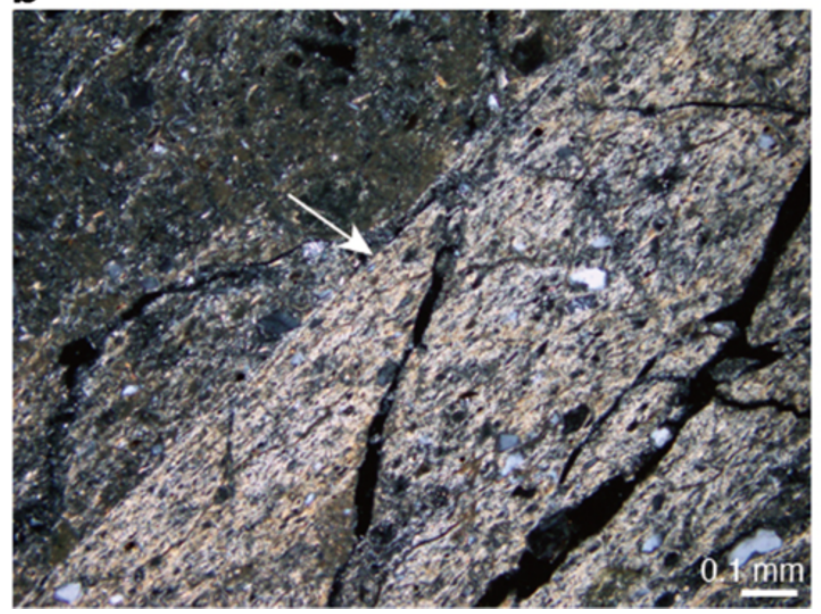

d

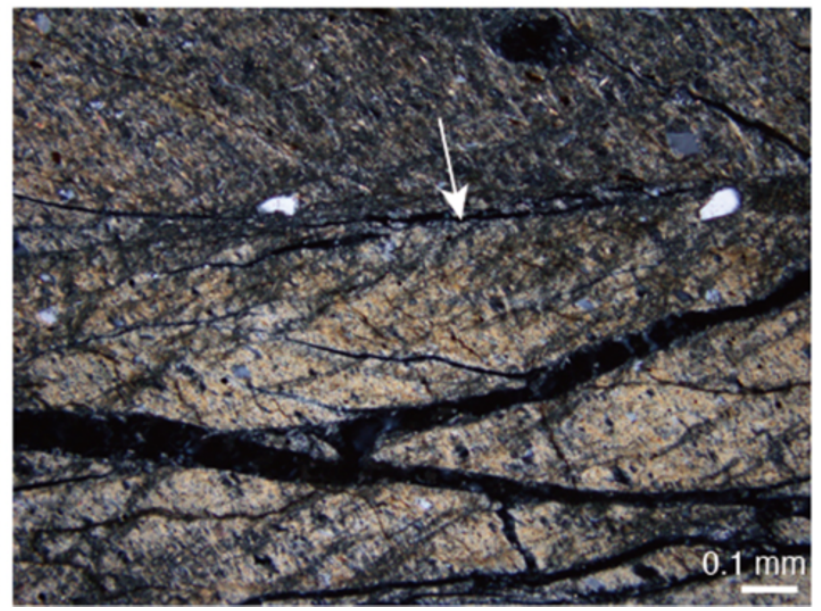

Figure $\mathbf{5}$ Microstructures of fault gouges. Fault gouges in (a) and (b) are from the megasplay fault zone, with white arrows indicating their upper boundaries. Fault gouges in (c) and (d) are from the plate-boundary fault zone, with a white double and single arrow indicating the gouge zone and the upper boundary of the fault gouge, respectively. All photomicrographs were taken under cross-polarized light. 
the gouges is consistent with the higher bulk density of gouges compared to the surrounding breccias.

The gouges in the megasplay fault and the plateboundary thrust appear to record evidence for frictional heating associated with coseismic slip even at shallow depths of 271 and 438 mbsf, respectively, as indicated by optical reflectance anomalies in vitrinite (Sakaguchi et al. 2011). Vitrinite is a constituent of bituminous coal. Vitrinite reflectance $\left(R_{o}\right)$ is an indicator of the thermal maturation of coal, which increases with increasing temperature and heating duration. Since an increase in $R_{o}$ is an irreversible reaction, it is expected to record the maximum temperature. Sakaguchi et al. (2011) measured $R_{o}$ across the dark gouges in the megasplay fault and the plate-boundary thrust and identified zones of anomalous $R_{o}$ values symmetrically distributed around the gouges (Figure 6). $R_{o}$ values were seen to be largest within the gouges and decreased with distance away. The maximum temperatures estimated from the measured $R_{o}$ anomalies were $390 \pm 50^{\circ} \mathrm{C}$ in the megasplay fault and $330 \pm 50^{\circ} \mathrm{C}$ in the plate-boundary thrust, both of which are much higher than the ambient temperatures of $<20 \pm 15^{\circ} \mathrm{C}$. It is likely that these high temperatures are caused by the generation of frictional heat associated with earthquake faulting along the thin (approximately 2 to $10 \mathrm{~mm}$ ) gouges, while high $R_{o}$ values adjacent to the gouges could record the effects of heat diffusion away from the gouge zones (Sakaguchi et al. 2011).

Hirono et al. (2009) examined other temperature proxies (i.e., fluid-mobile trace elements, strontium isotopes, magnetic minerals, inorganic carbon content, and Raman spectra of carbonaceous material) for the same gouge in the megasplay fault zone. These proxies successfully identified previous seismic slip on the Chelungpu thrust, including that attributed to the 1999 Chi-Chi earthquake $\left(M_{w} 7.6\right)$ in Taiwan (Hirono et al. 2006; Ishikawa et al. 2008). However, Hirono et al. (2009) did not detect any thermal anomaly. No detection of thermal anomaly may simply reflect the fact that vitrinite is more sensitive to increased heat than other temperature proxies. Alternatively, it is possible that the coseismic temperature does not exceed $300^{\circ} \mathrm{C}$ (Hirono et al. 2009), and/or the maximum temperature estimated from $R_{o}$ may have been overestimated (Kitamura et al. 2012; Furuichi et al. 2013). The kinetic model of Sweeney and Burnham (1990), which considers a first-order Arrhenius law, was used to calculate the maximum temperature from $R_{o}$ values (Sakaguchi et al. 2011). In this model, $R_{o}$ is related to the extent of the

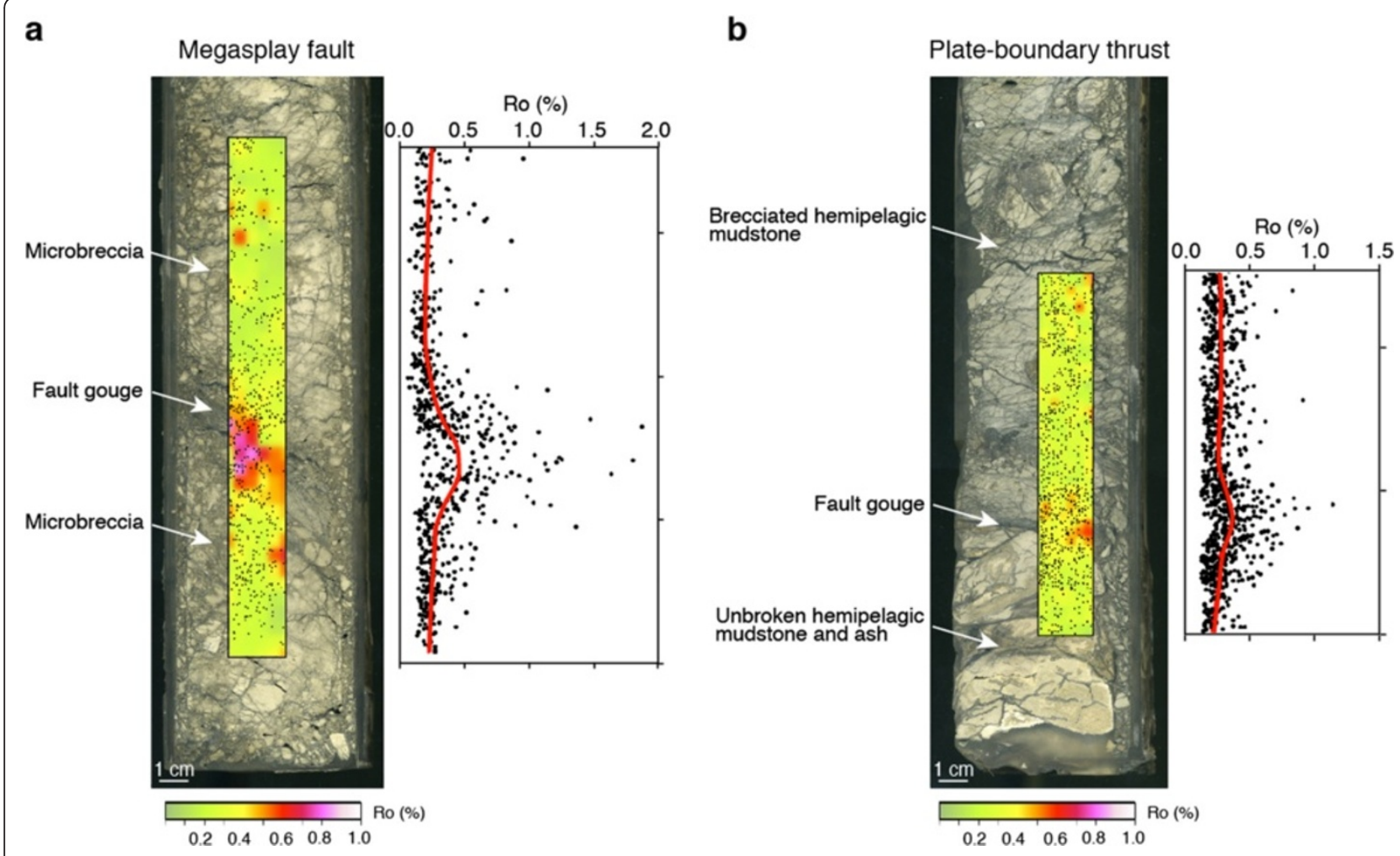

Figure 6 Distribution of vitrinite reflectance $\left(\boldsymbol{R}_{o}\right)$ across fault gouges (modified from Sakaguchi et al. 2011). (a) From the megasplay fault zone and (b) from the plate-boundary fault zone. Black dots on core surfaces indicate coal particles used for $R_{0}$ measurement. Red lines show smoothed $R_{0}$ curves. See Figures 2 and 3 for locations of fault gouges. 
parallel chemical reactions $(F)$ associated with thermal maturation, which is described by the empirical relationship:

$$
R_{0} \%=e^{(-1.6+3.7 F)}
$$

However, it is not possible to apply this chemical kinetic model to short-lived thermal events such as frictional heating on faults. In fact, recent high-velocity $(1.3 \mathrm{~m} / \mathrm{s})$ friction experiments on a mixture of $95 \mathrm{wt} \%$ clay-rich powder and $5 \mathrm{wt} \%$ coal grains from the host rock of the megasplay fault gouge and the Kumano forearc basin in the Nankai subduction zone, respectively, demonstrated that $R_{o}$ can be increased by high-velocity shearing, but the $R_{o}$ determined from the kinetic model of Sweeney and Burnham (1990) is greater than the $R_{o}$ measured after the experiments (Furuichi et al. 2013). Fulton and Harris (2012) conducted numerical modeling to explain the spatial distribution of $R_{o}$ across the fault gouges using the thermal model for frictional heat generation and diffusion with finite thickness, coupled with the kinetic model of Sweeney and Burnham (1990). Their results indicate that very large coseismic slip of several tens of meters is necessary to account for both the peak and spatial extent of anomalous $R_{o}$ found in and around the fault gouges. Thus, estimation of coseismic temperature using the kinetic model of Sweeney and Burnham (1990) is problematic and requires further investigation. However, the increase in $R_{o}$ in the fault gouges even at shallow depths is evident, and several experimental studies have demonstrated that $R_{o}$ values can increase during highvelocity shearing on short timescales comparable to an approximately 10-s earthquake rise time (O'Hara et al. 2006; Kitamura et al. 2012; Furuichi et al. 2013).

Yamaguchi et al. (2011b) reported geochemical and mineralogical anomalies in the same fault gouge in the

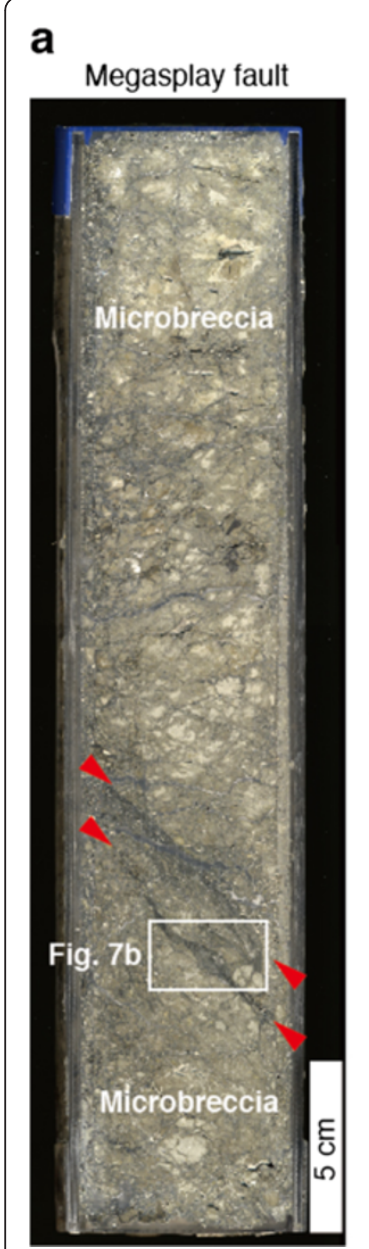

b
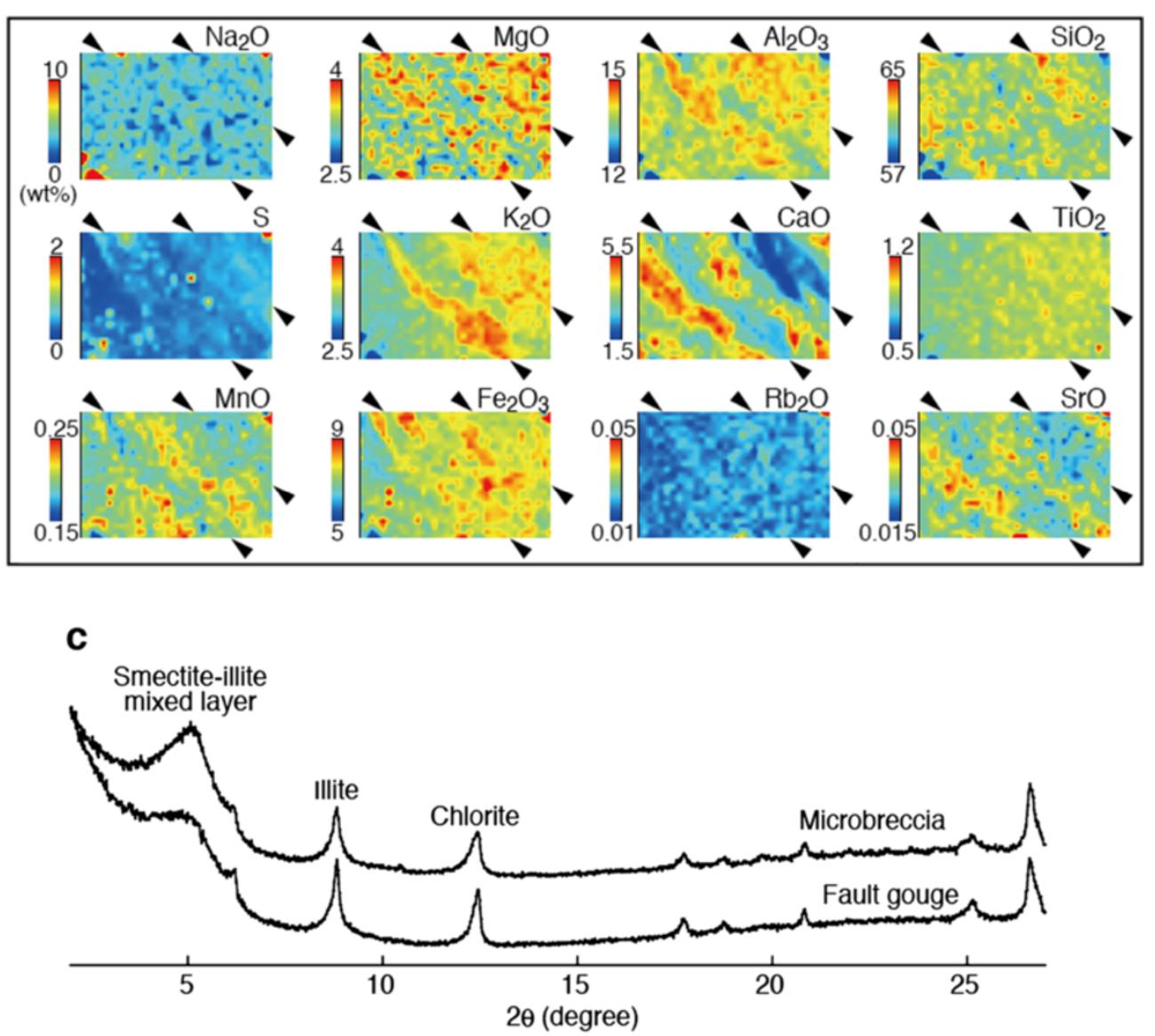

Figure 7 Geochemical and mineralogical data showing transformation of Ca-smectite into illite in the fault gouge. Modified from Yamaguchi et al. (2011b). See Figure 2 for the location of the fault gouge. (a) Photograph of the fault gouge in the megasplay fault zone showing the XRF mapping area in (b) (white rectangle). Red triangles indicate fault gouge (upper) and fragmented gouge (lower) in microbreccia. (b) Compositional maps across fault gouges (solid triangles). (c) XRD patterns for fault gouge and microbreccia shown in (a). 
megasplay fault zone where Sakaguchi et al. (2011) detected anomalous $R_{o}$ values. They conducted a nondestructive X-ray fluorescence (XRF) analysis using a core-imaging scanner and X-ray diffraction (XRD) analysis on the fault gouge and surrounding microbreccia. Their compositional maps indicate that the fault gouge is chemically enriched in $\mathrm{Al}$ and $\mathrm{K}$, and depleted in $\mathrm{Ca}$ and $\mathrm{Sr}$ relative to the surrounding breccias, which is consistent with the XRD data showing that the fault gouge has a higher illite content in illite-smectite mixedlayer clays (Figure 7). These results suggest that the transformation of Ca-smectite into illite has progressed in the fault gouge. It has been proposed that the transformation of smectite to illite in the shear zone occurs by dissolution and recrystallization processes, shear-related deformations, and frictional heating (Yan et al. 2001; Hirono et al. 2008; Casciello et al. 2011). The coexistent anomalies of $R_{o}$ and the clay mineralogy anomalies in the gouges suggest that frictional heating is the most likely cause for the illitization within the gouges (Yamaguchi et al. 2011b).

Fault zone structures and analyses of approximately 2 - to 10 -mm-thick dark gouges in the megasplay fault and the plate-boundary thrust suggest that earthquake rupture propagated to shallow depths. Clay-rich materials taken from the shallow megasplay fault and shallow plate-boundary thrust show velocity-strengthening frictional behavior at low slip rates, suggesting that earthquake nucleation is unlikely to occur at shallow depths (Ikari and Saffer 2011). However, the high-velocity $(1.3 \mathrm{~m} / \mathrm{s})$, wet (water-saturated) friction experiments on clay-rich materials taken from gouge host rocks and pure clays demonstrated that earthquake rupture propagates easily through clay-rich fault gouge by high-velocity weakening associated with thermal pressurization, which is marked by low peak and steady-state friction, and a very small slip weakening distance and fracture energy (Ujiie and Tsutsumi 2010; Faulkner et al. 2011). The permeabilities of the fault zone materials in the megasplay fault and the plate-boundary thrust are in the orders of $10^{-20}$ to $10^{-18} \mathrm{~m}^{2}$ (Ikari et al. 2009; Tanikawa et al. 2012). Unless dilatancy hardening operates in lowpermeability gouges (Rudnicki and Chen 1988; Segall and Rice 1995), water is not expected to be able to escape from a shear zone during earthquake faulting (Lachenbruch 1980; Mase and Smith 1987; Rice 2006). Therefore, when frictional heat is generated along narrow gouges approximately 2 - to 10 - $\mathrm{mm}$ thick, thermal pressurization is likely to occur even at shallow depths. This suggests that a shallow fault exhibiting stable, velocitystrengthening behavior at low slip rates may be weakened by thermal pressurization. Recent numerical modeling considering the rate- and state-dependent friction constitutive law, and high-velocity weakening due to rapid shear heating of pore fluids, has revealed that unstable slip occurs even in fault segments where velocity-strengthening occurs at low slip rates (Shibazaki et al. 2011; Noda and Lapusta 2013).

In summary, fault rock analyses and experimental investigations using fault zone materials highlight that the propagation of seismic slip to shallow portions of the megasplay fault and the plate-boundary thrust is likely to have occurred during subduction earthquakes (Figure 8), which would then have facilitated the generation of tsunamis in the Nankai subduction zone.

\section{Fault rocks in exhumed accretionary complexes}

Examination of fault rocks exhumed from various depths in subduction zones is essential in order to understand fault slip behaviors such as dynamic earthquake rupture, low-frequency tremor and earthquakes, slow slip events, and post-seismic and interseismic creep. In particular, tectonic mélanges in exhumed accretionary complexes can be regarded as fault rocks that formed along subduction plate boundaries and are thus expected to record earthquake faulting in subduction zones (Kimura et al. 2012). Mélanges are characterized by competent blocks (e.g., sandstone) in an incompetent (e.g., mudstone) matrix. Fagereng and Sibson (2010) pointed out that variation in the ratio of competent to incompetent material causes spatial variations in shear strength, viscosity, shear strain rate, and fault slip behavior. They suggested that localization of shear occurs along lithological boundaries or within competent blocks, while distributed shear is accommodated by foliated phyllosilicates in the incompetent matrix. The competent blocks composed of strong minerals tend to show high frictional strength and velocity-weakening behavior, whereas the foliated phyllosilicates commonly exhibit low frictional strength and velocity-strengthening behavior (Collettini et al. 2011; Ikari et al. 2011). It is likely that the heterogeneity of mélange affects aseismic slip and earthquake nucleation (Fagereng and Sibson 2010). Recently, Rowe et al. (2013) compiled data on the thicknesses of subduction thrusts at depths of $<1$ to $15 \mathrm{~km}$. Although mélanges can be several hundreds of meters thick, a simultaneously active part of a subduction plate boundary consists of one or multiple fault strands with a thickness of 5 to $35 \mathrm{~m}$, which are sharply cut by discrete slip surfaces with thicknesses of $<1$ to $20 \mathrm{~cm}$. These observations suggest that dynamic earthquake rupture occurs in highly localized slip zones with thickness of $<1$ to $20 \mathrm{~cm}$, while post-seismic and interseismic creep is generated in single to several strands with thicknesses of 5 to $35 \mathrm{~m}$ (Rowe et al. 2013). In the following subsections, we show representative results of fault rocks studies conducted in exhumed accretionary complexes.

\section{Frictional melting}

Pseudotachylytes Pseudotachylytes (i.e., solidified frictional melts produced during seismic slip) have been 


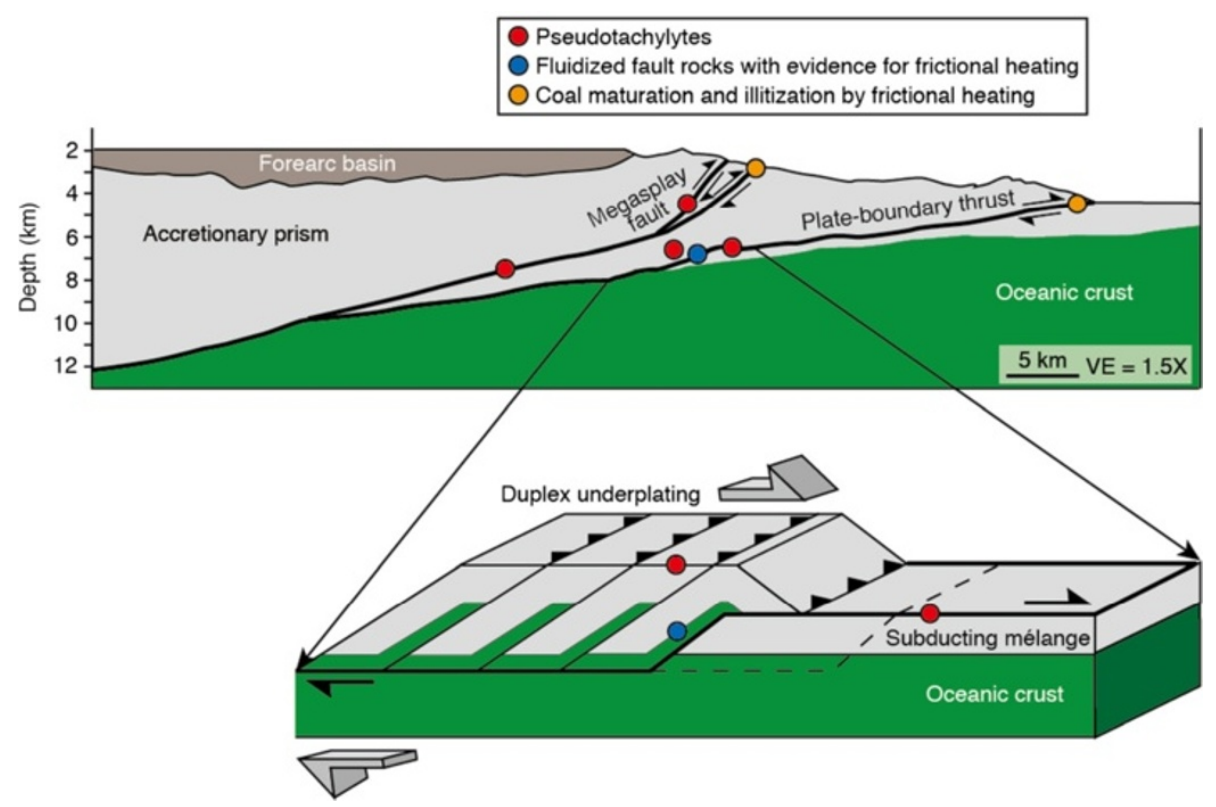

Figure 8 Schematic profile of the Nankai accretionary prism offshore the Kii Peninsula, southwest Japan. Orange dots indicate locations of fault gouges in which coal maturation and illitization were found by drilling into the shallow portions of the megasplay fault and the plate-boundary thrust. The tectonic setting of the duplex underplating of the tectonic mélange and basalt is shown on the profile. Tectonic settings of pseudotachylytes (red dots) and fluidized fault rocks (blue dots), which are identified in the Shimanto accretionary complex (the on-land analog of the Nankai accretionary prism), are shown in the profile.

found in exhumed accretionary complexes (Ikesawa et al. 2003; Kitamura et al. 2005; Rowe et al. 2005; Mukoyoshi et al. 2006; Okamoto et al. 2006; Ujiie et al. 2007b; Meneghini et al. 2010; Hashimoto et al. 2012). Geological settings associated with pseudotachylyte-bearing faults are plate-boundary thrusts, roof thrusts of duplex structures, and megasplay faults (or out-of-sequence thrusts) (Figure 8) that were active at depths of 2.5 to $14 \mathrm{~km}$ and temperatures of $160^{\circ} \mathrm{C}$ to $320^{\circ} \mathrm{C}$ (Ikesawa et al. 2003; Kitamura et al. 2005; Rowe et al. 2005; Mukoyoshi et al. 2006; Okamoto et al. 2006; Hashimoto et al. 2012). In many cases, pseudotachylyte-bearing faults develop near the boundary between argillaceous mélange and relatively coherent sandstone, and pseudotachylytes are hosted in either foliated or non-foliated mélange-derived cataclasites (Figure 9a). Pseudotachylytebearing fault zones can range in thickness from less than $1 \mathrm{~m}$ to tens of meters. Pseudotachylyte-bearing fault zones in the exhumed accretionary complexes commonly contain quartz, calcite, ankerite, and laumontite veins and their fragments, which are consistent with fluid-infiltrated conditions (Ikesawa et al. 2003; Mukoyoshi et al. 2006; Okamoto et al. 2006; Ujiie et al. 2007b) and are in contrast to pseudotachylytes that form in crystalline rocks under dry conditions (Sibson and Toy 2006). One explanation for the occurrence of pseudotachylytes in fluid-saturated fault zones is that seismic slip occurred along a thin slip zone with a high permeability/compressibility. In such a case, fluid could escape from the slip zone during earthquake faulting, generating temperatures high enough for frictional melting. Pseudotachylyte-bearing dark veins in the exhumed accretionary complexes are commonly thinner than a few millimeters (typically $1 \mathrm{~mm}$ ), which is consistent with the presence of a thin slip zone during earthquake faulting (Figure 9b).

The pseudotachylyte-bearing dark veins at outcrop are continuous and straight, but in places show the appearance of both fault and injection veins. The length of the injection veins is less than $10 \mathrm{~mm}$. Based on the following observations, the dark veins are thought to have originally been pseudotachylyte veins that subsequently suffered hydrothermal alteration: the dark veins locally preserve the embayed boundaries (Figure 9c) and are mostly composed of illite, which was possibly derived from hydrothermal alteration; mineralized veins are present along the dark veins (Figure 9c); and some portions of the dark veins and injection veins survived alteration and are preserved as evidence for frictional melting (Figure 9d). Under plane-polarized light, the unaltered pseudotachylytes are characterized by the presence of subangular to subrounded grains of quartz and feldspar, and small dark grains in the transparent matrix. Under cross-polarized light, the matrix is dark and optically isotropic.

Examination under a scanning electron microscope (SEM) and transmission electron microscope (TEM) has 


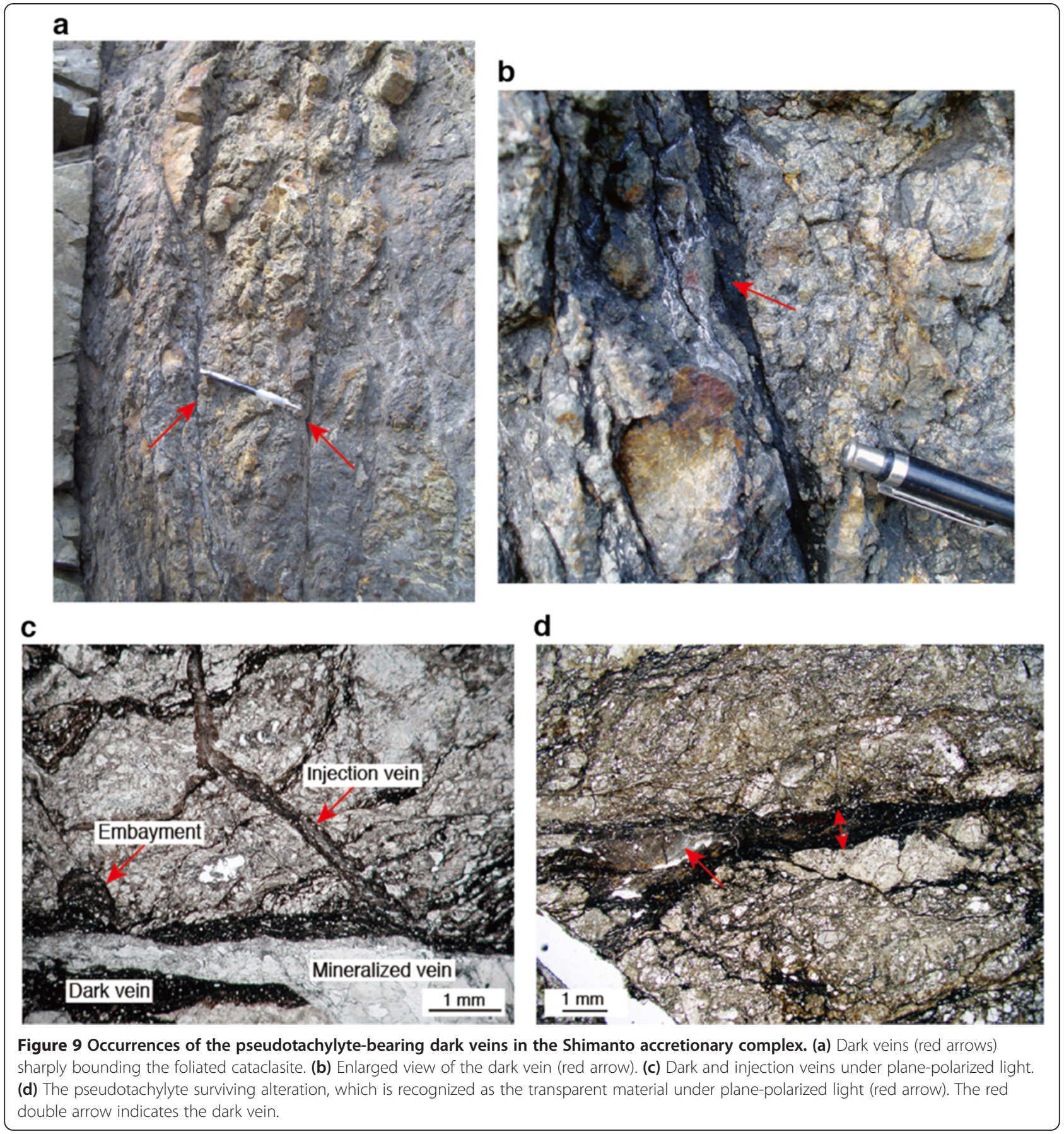

revealed the following evidence for frictional melting (Figure 10 and see also Mukoyoshi et al. 2006; Okamoto et al. 2006; Ujiie et al. 2007b; Meneghini et al. 2010): a glassy matrix, grains with irregular and embayed margins, vesicles and amygdules, Fe-rich spherules, idiomorphic acicular microlites of mullite or muscovite, and tabular zoned microlites of plagioclase. Acicular and tabular microlites were reported from the $1-\mathrm{mm}$ and 10- to 100-mm-thick pseudotachylytes, respectively (Rowe et al. 2005; Mukoyoshi et al. 2006; Ujiie et al. 2007b; Meneghini et al. 2010), with the latter being exceptionally thick compared to typical pseudotachylytes (Sibson 1975, 2003; Di Toro and Pennacchioni 2004). Different crystal morphologies may be the result of variations in the cooling rate of the melt, although other parameters (e.g., the presence and abundance of nuclei for crystallization) may also contribute (Lofgren 1980; Corrigan 1982). The tabular morphology of plagioclase microlites is consistent with slow cooling in an exceptionally thick melt (Meneghini et al. 2010). The presence of embayed grains, vesicles, and 


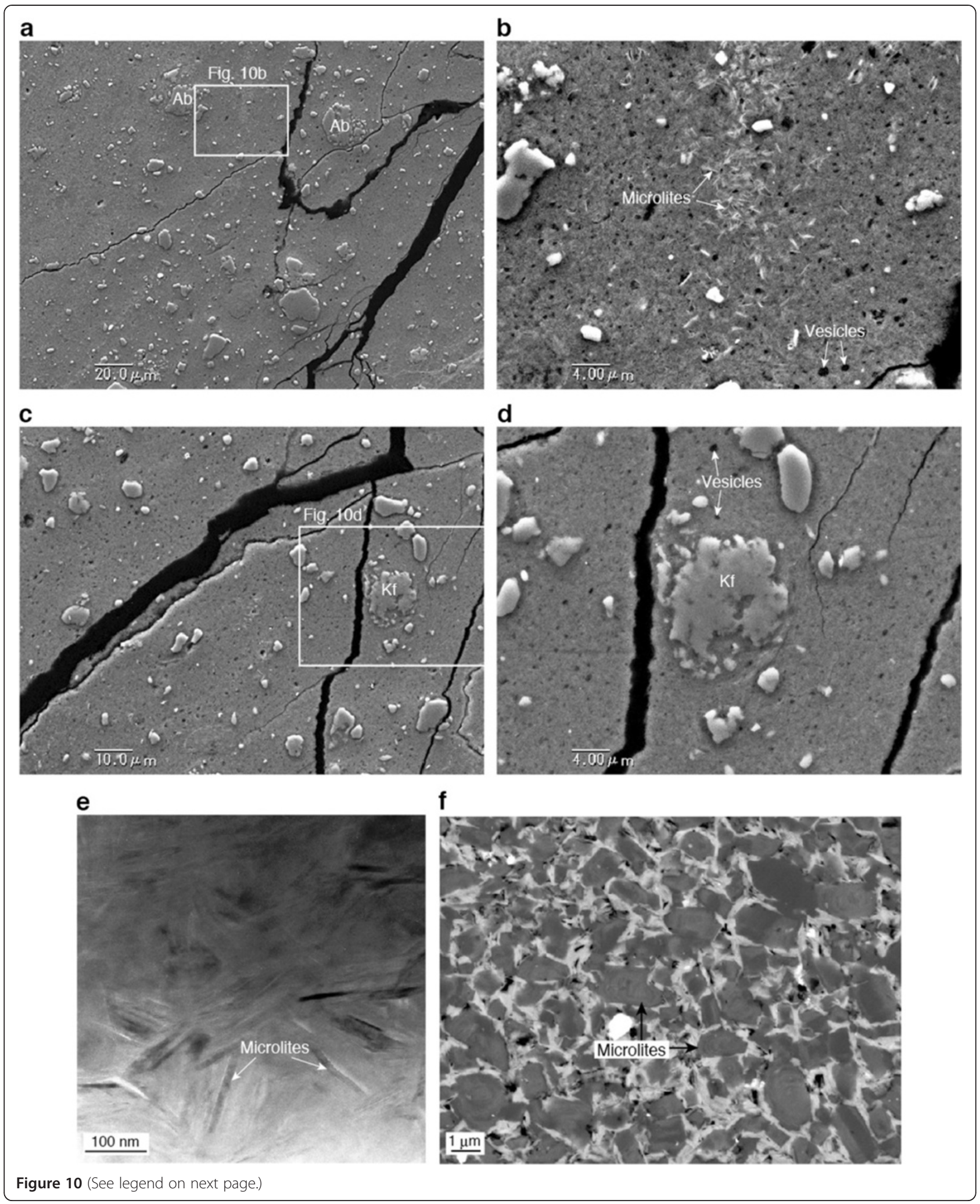


(See figure on previous page.)

Figure 10 Microstructures of pseudotachylytes. (a-e) Pseudotachylytes from the Shimanto accretionary complex. (f) Pseudotachylyte from the Kodiak accretionary complex (modified from Meneghini et al. 2010). (a) Back-scattered electron image of pseudotachylyte showing fragments in a glassy matrix resulting from rapid cooling of the frictional melt. Albite grains (Ab) with irregular and embayed margins are present in the homogeneous matrix. (b) Vesicles and idiomorphic acicular microlites of muscovite in the matrix. Location of the image is shown in (a). (c) Back-scattered electron image of pseudotachylyte showing an embayed K-feldspar grain (Kf) in the homogeneous matrix. (d) Enlarged view of the embayed K-feldspar grain (Kf), suggesting marginal melting. Vesicles are visible in the matrix. Location of the image is shown in (c). (e) TEM image of pseudotachylyte showing idiomorphic acicular microlites of mullite in a homogeneous, glassy matrix. (f) Back-scattered electron image of pseudotachylyte showing tabular zoned microlites of plagioclase.

Fe-rich spherules in the homogeneous, glassy matrix was successfully reproduced in the pseudotachylytes produced by high-velocity $(1.3 \mathrm{~m} / \mathrm{s})$ friction experiments on argillite from the pseudotachylyte host rock in the Shimanto accretionary complex (Ujiie et al. 2009).

The chemical composition of the pseudotachylyte matrix determined by an electron probe microanalyzer (EPMA) is similar to that of illite (Table 1), which is consistent with the selective melting of phyllosilicates due to their low shear yield strength, fracture toughness, and thermal conductivity (Spray 1992). Heating experiments on illite reveal that illite melts at approximately $950^{\circ} \mathrm{C}$ to $1,200^{\circ} \mathrm{C}$ and that crystallization and melting of mullite occur at $1,100^{\circ} \mathrm{C}$ and $\geq 1,400^{\circ} \mathrm{C}$, respectively (Grim and Bradley 1940; Moecher and Brearley 2004; McConville and Lee 2005). The rounded and embayed shapes of albite and K-feldspar grains (Figure 10) are attributed to disequilibrium marginal melting, which has occurred due to a decrease in the melting temperature of feldspar caused by the release of $\mathrm{OH}^{-}$from hydrous phases or by viscous shear heating at $>1,100^{\circ} \mathrm{C}$ (Spray 1992). It is therefore considered that the frictional melts reached a minimum temperature of $1,100^{\circ} \mathrm{C}$.

The common feature of frictional melting is that hydrous minerals melt preferentially, whereas refractory minerals such as quartz survive as clasts (Allen 1979; Maddock 1992; Magloughlin 1992; Magloughlin and Spray 1992; Spray 1992; Otsuki et al. 2003). As frictional melting exhibits disequilibrium characteristics, a higher degree of melting leads to a greater degree of melting of refractory minerals. Thus, the chemical composition of a pseudotachylyte matrix would be expected to change as the degree of melting increases. However, the chemical composition of the pseudotachylyte matrix from the Shimanto accretionary complex samples remained constant (i.e., similar to that of illite), despite the volume fraction $(\phi)$ of unmelted grains ranging from $9 \%$ to $26 \%$ (Table 1). These variations in volume fraction of unmelted grains cannot be explained by differences in the degree of melting and instead may reflect differences in the initial volume fraction of illite prior to frictional melting (Ujiie et al. 2007b). It is likely that the illite was either derived from

Table 1 Average chemical composition of pseudotachylyte matrix, and volume fraction and average aspect ratio of unmelted grains

\begin{tabular}{|c|c|c|c|c|c|c|c|}
\hline & & & & & & Okitsu area & \\
\hline & $M g-1$ & $M g-2$ & $M g-3$ & $\mathrm{Mg}-4$ & Ok-1 & Ok-2 & Ok-3 \\
\hline$\varphi$ & 0.09 & 0.26 & 0.26 & 0.26 & 0.13 & 0.18 & 0.12 \\
\hline$R$ & 1.58 & 1.56 & 1.55 & 1.54 & 1.39 & 1.5 & 1.41 \\
\hline$n$ & 11 & 6 & 13 & 5 & 13 & 8 & 10 \\
\hline $\mathrm{SiO}_{2}$ & $52.55 \pm 0.85$ & $51.80 \pm 1.50$ & $52.79 \pm 0.31$ & $51.65 \pm 1.24$ & $53.40 \pm 0.92$ & $53.05 \pm 0.66$ & $52.46 \pm 1.13$ \\
\hline $\mathrm{TiO}_{2}$ & $0.27 \pm 0.08$ & $0.16 \pm 0.11$ & $0.08 \pm 0.01$ & $0.13 \pm 0.03$ & $0.14 \pm 0.07$ & $0.29 \pm 0.05$ & $0.21 \pm 0.02$ \\
\hline $\mathrm{Al}_{2} \mathrm{O}_{3}$ & $30.22 \pm 0.65$ & $27.88 \pm 1.15$ & $27.97 \pm 0.00$ & $27.03 \pm 0.58$ & $29.25 \pm 0.80$ & $29.03 \pm 0.37$ & $28.92 \pm 0.36$ \\
\hline $\mathrm{FeO}$ & $2.55 \pm 0.48$ & $4.68 \pm 1.88$ & $3.72 \pm 0.12$ & $5.32 \pm 0.39$ & $2.40 \pm 0.49$ & $2.32 \pm 0.09$ & $2.28 \pm 0.11$ \\
\hline $\mathrm{MnO}$ & $0.21 \pm 0.29$ & $0.16 \pm 0.04$ & $0.13 \pm 0.01$ & $0.19 \pm 0.02$ & $0.03 \pm 0.02$ & $0.05 \pm 0.02$ & $0.02 \pm 0.01$ \\
\hline $\mathrm{MgO}$ & $1.63 \pm 0.08$ & $1.96 \pm 0.29$ & $1.60 \pm 0.08$ & $2.15 \pm 0.15$ & $2.51 \pm 0.14$ & $2.52 \pm 0.14$ & $2.51 \pm 0.05$ \\
\hline $\mathrm{CaO}$ & $0.55 \pm 0.08$ & $0.66 \pm 0.10$ & $0.94 \pm 0.49$ & $0.57 \pm 0.02$ & $0.45 \pm 0.40$ & $0.33 \pm 0.04$ & $0.42 \pm 0.33$ \\
\hline $\mathrm{Na}_{2} \mathrm{O}$ & $0.13 \pm 0.02$ & $0.13 \pm 0.01$ & $0.11 \pm 0.03$ & $0.15 \pm 0.01$ & $0.06 \pm 0.02$ & $0.06 \pm 0.01$ & $0.06 \pm 0.01$ \\
\hline $\mathrm{K}_{2} \mathrm{O}$ & $7.82 \pm 0.35$ & $6.92 \pm 0.51$ & $6.97 \pm 0.08$ & $6.88 \pm 0.14$ & $6.90 \pm 0.81$ & $8.38 \pm 0.52$ & $8.23 \pm 0.19$ \\
\hline Total & 95.93 & 94.34 & 94.30 & 94.11 & 95.15 & 96.04 & 95.12 \\
\hline Missing mass & 4.07 & 5.66 & 5.7 & 5.89 & 4.85 & 3.96 & 4.88 \\
\hline
\end{tabular}

Modified from Ujiie et al. (2007b). $\varphi$, volume fraction of unmelted grains; $R$, average aspect ratio of unmelted grains; $n$, numbers of analyses. 
hydrothermal alteration, which may be a precursor to frictional melting (Magloughlin 1992), or from the alteration of the pseudotachylyte matrix. The presence of illite and chlorite was also reported in pseudotachylyte layers from the Kodiak accretionary complex, Alaska, and was interpreted as representing the alteration of the pseudotachylyte matrix (Meneghini et al. 2010). Pseudotachylytes are rarely preserved in a recognizable form due to recrystallization, alteration, and subsequent deformation by cataclastic and crystal-plastic mechanisms (Kirkpatrick and Rowe 2013). In accretionary complexes, the primary control on the scarcity of pseudotachylytes appears to result from hydrothermal alteration in fluid-saturated fault zones.

Effects of frictional melting on earthquake faulting The estimation of shear resistance during frictional melting is crucial to evaluate coseismic fault behavior. Earthquake faulting associated with frictional melting is controlled by factors such as strain rate, melt thickness, fault roughness, melt escape from the slip interface, and melt viscosity (Fialko and Khazan 2005; Nielsen et al. 2008). In this section, we show how shear resistance was determined from pseudotachylytes in exhumed accretionary complexes.

By assuming the Arrhenian temperature dependence of melt viscosity, the matrix viscosity of frictional melts was calculated using the Shaw (1972) model (Spray 1993; Ujiie et al. 2007b; Kirkpatrick et al. 2012):

$$
\eta(T)=A \exp \left(\frac{B}{T}\right)
$$

where $T$ is the absolute temperature, and $A$ and $B$ are the reference viscosity (temperature-independent prefactor) and the activation temperature, respectively. This model is able to predict the melt viscosity from the melt composition and has been used for calculation of the temperature dependence of melt viscosity under anhydrous and hydrous conditions. In the case of the frictional melt formed in accretionary complexes, the chemical composition of the pseudotachylyte matrix listed in Table 1 was used for the calculation of the matrix viscosity. It is considered likely that the frictional melting of illite produced the hydrous melt. The water content in the frictional melt estimated from the missing mass in the pseudotachylyte matrix is $3.96 \%$ to $5.89 \%$ (Table 1), which is comparable to the content of structural water from the $\mathrm{OH}^{-}$ions in illite (Deer et al. 1992). Since most of the adsorbed and interlayer water of the illite would be driven off under the temperature conditions in pseudotachylyte-bearing fault zones $\left(160^{\circ} \mathrm{C}\right.$ to $320^{\circ} \mathrm{C}$ ), the estimated water content appears to be reasonable. The calculated matrix viscosity at a minimum melting temperature of $1,100^{\circ} \mathrm{C}$ is low, ranging from 21 to $130 \mathrm{~Pa}$ s (Figure 11).

In contrast, frictional melts may show non-Arrhenian Newtonian viscosity (Dingwell and Webb 1989; Dingwell et al. 1993). The non-Arrhenian temperature dependence of the melt viscosity was expressed by the Vogel-FulcherTammann (VFT) equation based on $>1,770$ measurements of viscosity on multicomponent anhydrous and hydrous silicate melts:

$$
\log \eta=A+\frac{B}{T-C}
$$

where $A, B$, and $C$ are adjustable parameters (Giordano et al. 2008). We calculated the non-Arrhenian temperature dependence of the matrix viscosity of frictional melt using the viscosity calculator of Giordano et al. (2008) and adopted the same chemical composition of the pseudotachylyte matrix and water content as used for the Arrhenian temperature dependence of the matrix viscosity of frictional melt (Table 1). The fluorine content is assumed to be zero. The matrix viscosity at $1,100^{\circ} \mathrm{C}$ is in the order of 20 to $111 \mathrm{~Pa} \mathrm{~s}$, which is of the same order as that used to consider the Arrhenian temperature dependence (Figure 11).

Unmelted grains and bubbles influence the viscosity of a melt (Metzner 1985; Mueller et al. 2010); for example, the viscosity of silicate melts becomes nonNewtonian when the volume fraction of the crystals in melts exceeds 40\% (Lejeune and Richet 1995). The relative viscosity (i.e., the ratio of the viscosity with solid

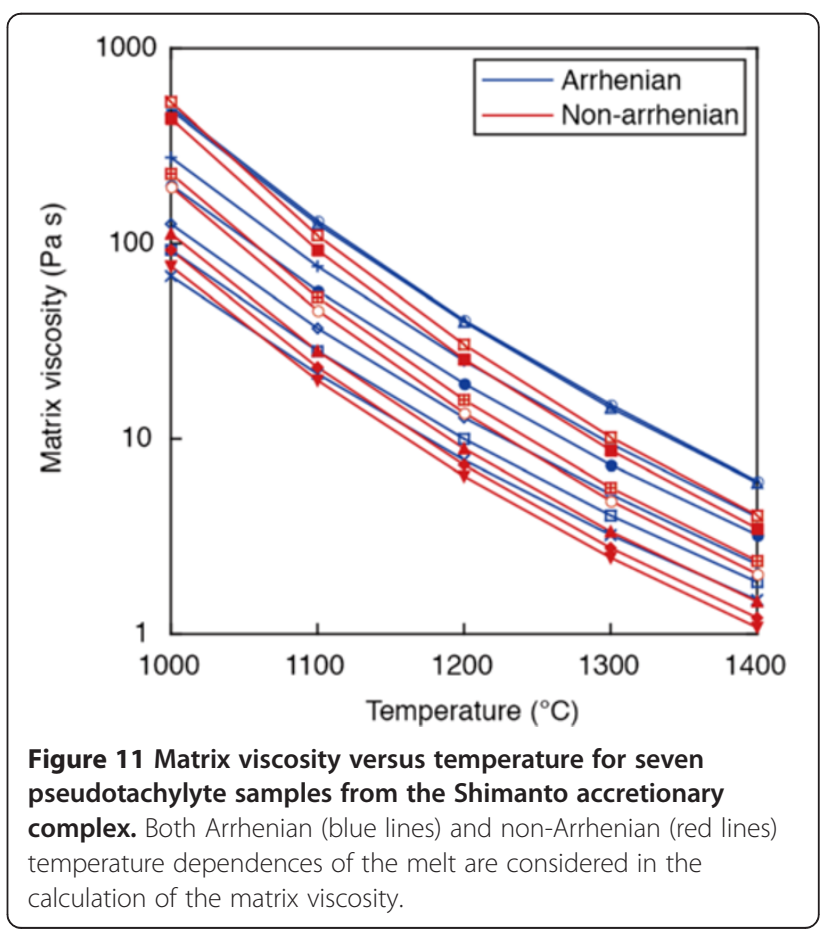


grains to the inclusion-free fluid viscosity) can be expressed as (Kitano et al. 1981):

$$
\eta_{r}=\left[1-\left(\frac{\phi}{A}\right)\right]^{-2}
$$

with $A=0.54-0.0125 R$, where $A$ is the parameter related to the packing geometry of solid grains, and $R$ is the average aspect ratio of the unmelted grains determined from SEM back-scattered electron images (Table 1). The Arrhenian and non-Arrhenian temperature dependence of the viscosity of the frictional melt at $1,100^{\circ} \mathrm{C}$ was estimated to be in the range of 85 to 290 and 79 to $258 \mathrm{~Pa}$ s, respectively. The volume fraction of vesicles in the pseudotachylyte is less than 5\%; therefore, the effect of the bubbles on the bulk viscosity would be negligible.

The viscosity of the frictional melt in accretionary complexes is low and is independent of the Arrhenian and non-Arrhenian temperature dependence. This low viscosity is attributed to the high melting temperature of $\geq 1,100^{\circ} \mathrm{C}$, the water content of illite, and the small volume fraction of unmelted grains. The seismic slip along the thin (mostly less than a few millimeters in thickness) layer would induce the high heat production rate and temperature, which in turn would reduce the viscosity of the frictional melt. Assuming the Arrhenian Newtonian viscosity of the frictional melt, the shear resistance $(\tau)$ along the melt layer is expressed as:

$$
\tau=\eta \frac{d \gamma}{d t}
$$

where $\eta$ is the viscosity of the frictional melt and $d y / d t$ is the shear strain rate. Considering $\tau$ along a $1-\mathrm{mm}$-thick melt layer at a slip rate of $1 \mathrm{~m} / \mathrm{s}$ and $\eta$ at a minimum melting temperature of $1,100^{\circ} \mathrm{C}, \tau$ is in the range of 0.1 to $0.3 \mathrm{MPa}$. The estimated shear resistance could provide a lower bound of the melt strength because the calculation assumes a Newtonian rheology.

Provided that most of the mechanical work during earthquake faulting is converted into heat, the shear resistance of the frictional melt is estimated as (Sibson 1975; Di Toro et al. 2005):

$$
\tau=\rho\left[C_{\mathrm{p}}\left(T_{\mathrm{m}}-T_{\mathrm{hr}}\right)+(1-\phi) H\right] \frac{w}{d}
$$

where $\rho=2,500 \mathrm{~kg} / \mathrm{m}^{3}$ is the rock density, $C_{p}=$ $1,000 \mathrm{~J} \mathrm{~kg}^{-10} \mathrm{C}^{-1}$ is the specific heat at constant pressure, $T_{\mathrm{m}}=1,100^{\circ} \mathrm{C}$ is the melting temperature, $T_{\mathrm{hr}}=180^{\circ} \mathrm{C}$ or $250^{\circ} \mathrm{C}$ is the host rock temperature, $\phi=0.09$ to 0.26 is the volume fraction of unmelted grains (Table 1), $H=3.2 \times$ $105 \mathrm{~J} \mathrm{~kg}^{-1}$ is the latent heat of fusion, $w=1 \mathrm{~mm}$ is the typical thickness of the melt layer, and $d=0.1$ to $4 \mathrm{~m}$ is the fault displacement during earthquakes of magnitudes $M 5$ to $M 8$ (Sibson 1989). The estimated shear resistance in the presence of the melt layer is in the order of 0.7 to $30.3 \mathrm{MPa}$ (Table 2), and the shear resistance calculated from Equation 5 is in the same order of that during an $M 8$ earthquake, which occurs in subduction zones.

The high-velocity friction experiments on argillite (typical host rock of pseudotachylytes in exhumed accretionary complexes) show the slip-strengthening behavior during the growth (thickening) of the melt layer (Ujiie et al. 2009), which is in contrast to the typical slip-weakening behavior during the formation of the melt layer in crystalline rocks (Tsutsumi and Shimamoto 1997; Hirose and Shimamoto 2005; Di Toro et al. 2006). This slip strengthening is attributed to dehydration increasing the viscosity of the melt layer, which may be specific to clay mineral-dominated argillite (Ujiie et al. 2009). On the other hand, the apparent coefficient of friction (the ratio of shear to normal stress) during slip strengthening progressively decreases from 1.2-1.4 to 0.4-0.6 when normal stress $\left(\sigma_{\mathrm{n}}\right)$ increases from 2.7 to $13.3 \mathrm{MPa}$ (Ujiie et al. 2009), which is consistent with theoretical predictions showing that viscous shear stress is almost independent of $\sigma_{\mathrm{n}}$ (Fialko and Khazan 2005). These experimental results on argillite imply that suppression of seismic slip due to viscous braking is expected at shallow depths in accretionary complexes if substantial melt dehydration occurs on the timescale of seismic slip. However, melt lubrication may occur at greater depths because the ratio of viscous shear stress to $\sigma_{\text {n }}$ progressively decreases with depth. Assuming the Newtonian rheology of the frictional melt, there may be a critical depth at which the frictional strength overcomes the viscous strength (Fialko and Khazan 2005):

$$
\eta \frac{d \gamma}{d t}<\mu \sigma_{\mathrm{n}}
$$

\begin{tabular}{|c|c|c|c|c|c|c|c|c|}
\hline \multirow{2}{*}{$\begin{array}{c}\text { Magnitude } \\
\text { M }\end{array}$} & \multirow{2}{*}{$\begin{array}{l}\text { Fault displacement } \\
\qquad d(\mathrm{~m})\end{array}$} & \multicolumn{7}{|c|}{ Shear resistance, $\tau(\mathrm{MPa})$} \\
\hline & & Mg-1 & $M g-2$ & $\mathrm{Mg}-3$ & $M g-4$ & Ok-1 & Ok-2 & Ok-3 \\
\hline 5 & 0.1 & 30.3 & 28.9 & 28.9 & 28.9 & 28.2 & 27.8 & 28.3 \\
\hline 6 & 0.4 & 7.6 & 7.2 & 7.2 & 7.2 & 7.1 & 7.0 & 7.1 \\
\hline 7 & 1 & 3.0 & 2.9 & 2.9 & 2.9 & 2.8 & 2.8 & 2.8 \\
\hline 8 & 4 & 0.8 & 0.7 & 0.7 & 0.7 & 0.7 & 0.7 & 0.7 \\
\hline
\end{tabular}

Table 2 Shear resistance of frictional melt at given fault displacement during earthquake of magnitudes M5 to M8 
where $d \gamma / d t$ is the shear strain rate, and $\mu$ is the friction coefficient. This may explain why pseudotachylytes in exhumed accretionary complexes were found at depths of $\geq 2.5 \mathrm{~km}$. Field observations and high-velocity friction experiments suggest that there is a transition from melt lubrication at greater depths to viscous braking at shallow depths. This could be one of the factors controlling the updip limit of the earthquake rupture zone in subductionaccretion complexes.

\section{Fluidization}

Fluidized fault rocks Fluidized fault rocks that are thought to be associated with earthquake faulting have been reported from various geological settings including normal faults (Smith et al. 2008, 2011), strike-slip faults (Monzawa and Otsuki 2003; Otsuki et al. 2003), and thrusts in the exhumed accretionary complexes (Rowe et al. 2005; Ujiie et al. 2007a; Boullier et al. 2009; Brodsky et al. 2009; Meneghini et al. 2010). Fluidization is a phenomenon by which granular materials in a suspension move freely, akin to molecules in a gas. Fluidization of granular materials occurs at high shear rates in a graininertia regime in which stress is transmitted by intergranular collisions (Bagnold 1954; Hanes and Inman 1985). Fluidized fault rocks may be then cohesive and are composed of extremely comminuted granular materials, which could be classified as ultracataclasite. Grains in the ultrafine-grained matrix are subangular to rounded, suggesting preferential abrasion and wearing of the grain corners. In the exhumed accretionary complexes, fluidized fault rocks were typically found in the argillaceous mélange and the underplated basalt (Figure 8).

In the early Tertiary accretionary complex of Kodiak Island, Alaska, the argillaceous mélange continuously develops along strike and has been interpreted as representing a paleo-subduction thrust that was subducted at depths of 12 to $14 \mathrm{~km}$ and temperatures of $230^{\circ} \mathrm{C}$ to $260^{\circ} \mathrm{C}$ (Byrne 1984; Fisher and Byrne 1987; Vrolijk et al. 1988). The approximately 0.3 -m-thick black and aphanitic fault rocks have developed in the 15- to 20-m-thick cataclasite that is derived from the argillaceous mélange (Rowe et al. 2005; Meneghini et al. 2010). The cataclasite is considered to represent episodes of localized deformation during subduction (Rowe et al. 2013). At outcrops, the black fault rock commonly exhibits deformational features consistent with fluidization (Rowe et al. 2005; Brodsky et al. 2009; Meneghini et al. 2010). While the lower boundary of the black rock is smooth and subplanar, the upper boundary is marked by flame-like intrusions of black rock into the cataclasite or flow structures and in places the black rock mixes with the overlying cataclasite (Figure 12a). The smoothly curved forms of the upper boundary and the ductilely deformed cataclasite adjacent to the black rock suggest the mobilization of black rock and cataclasite during intrusions. The cuspate form of the black rock intrusions suggests that it is less viscous than the overlying cataclasite. When the upper boundary is composed of a sandstone-rich mélange, the black rock shows sharp-walled injection veins into the overlying sandstone.

At the microscale scale, the black fault rock displays internal layering composed of ultracomminuted granular and crystalline materials, with the latter interpreted to represent tabular zoned microlites of plagioclase in pseudotachylytes (Meneghini et al. 2010). Flow, intrusion, and folding structures are observed along the boundary between granular and crystalline microlayers, suggesting that granular material and frictional melt deformed together in a ductile manner (Figure 12b). The granular material shows a homogeneous texture without any indication of slip localization. The intimate association of granular and crystalline microlayers suggests that fluidization is synchronous with frictional melting, but that it occurred prior to solidification of the frictional melt. In another case, clasts of granular and crystalline materials are found in the crystalline and granular microlayers, respectively, showing mutual brittle truncation and incorporation into the surrounding granular material (Figure 12c). This suggests that each earthquake faulting event occurred after the solidification of frictional melt and fluidized material.

In the Late Cretaceous to early Tertiary Shimanto accretionary complex of eastern Shikoku, the basalt slices and mélange (blocks of hemipelagic red shale, acidic tuff, and sandstone in a sheared argillaceous matrix) are imbricated along thrusts, representing a duplex underplating associated with the downward step of the subduction thrust at depths of 4 to $6 \mathrm{~km}$ and temperatures of $130^{\circ} \mathrm{C}$ to $150^{\circ} \mathrm{C}$ (Ikesawa et al. 2005) (Figure 8). One well-exposed duplex fault zone is a few tens of meters thick and is composed of basalt and basalt-derived fault rocks, in which slip was concentrated along a few-centimeters-thick ultracataclasite at mélange and basalt/basalt-derived foliated cataclasite boundary. The ultracataclasite is thought to have recorded the fluidization of comminuted granular materials (Ujiie et al. 2007a) given that the basalt-derived comminuted material is commonly injected into the overlying mélange, suggesting the mobilization of the fluidized material (Figure 12d); basalt- and mélange-derived comminuted materials are locally intermixed without shear surfaces, suggesting non-laminar (or turbulent) flow associated with fluidization (Figure 12e); fragmented counterparts (i.e., clast fragments that were originally part of a larger clast) are rarely identified in the injected materials, indicating that most of the fragmented counterparts moved away from one another in relation to fluidization (Monzawa and Otsuki 2003; Otsuki et al. 2003); and the homogeneous texture without discrete slip surfaces 


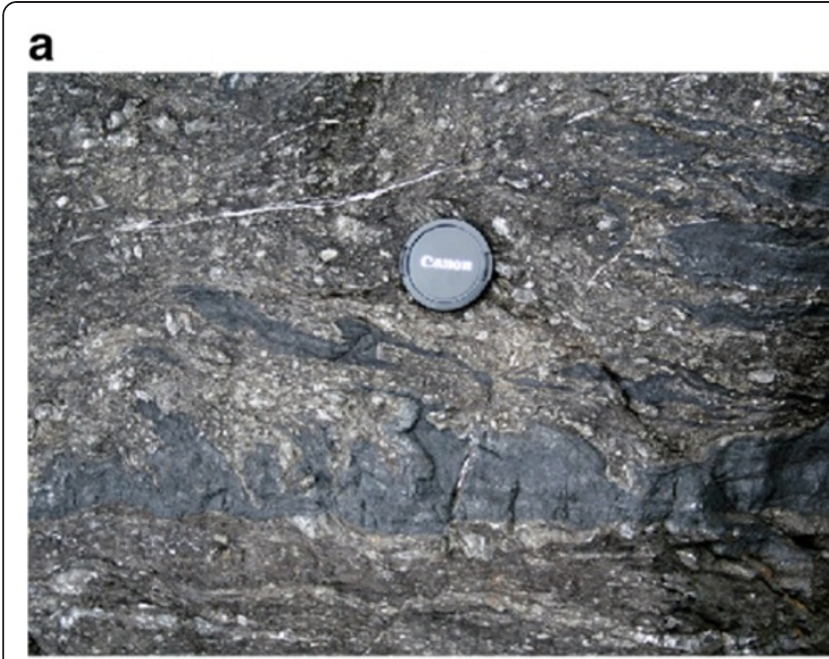

\section{d}

b

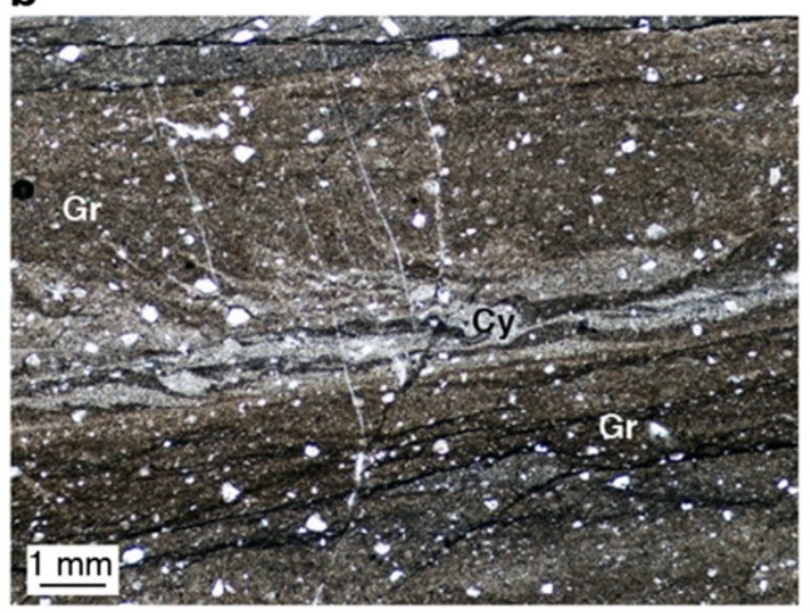

c

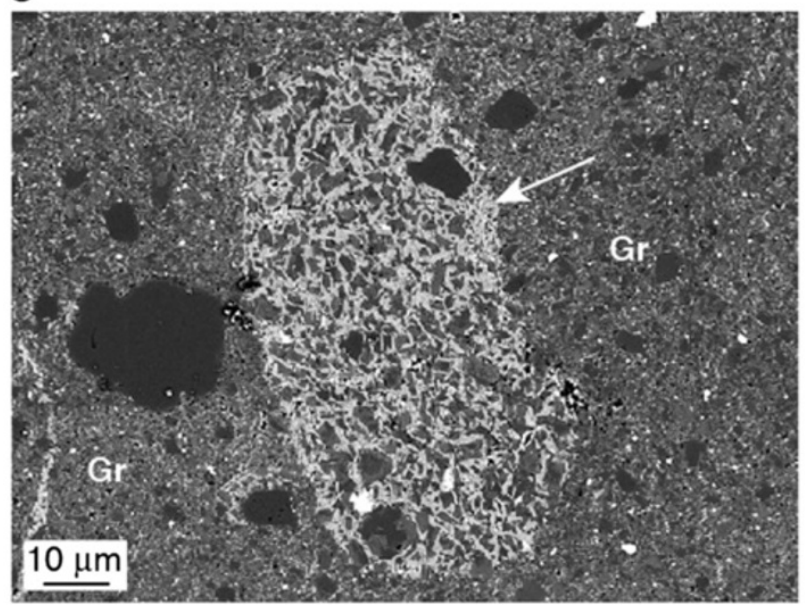

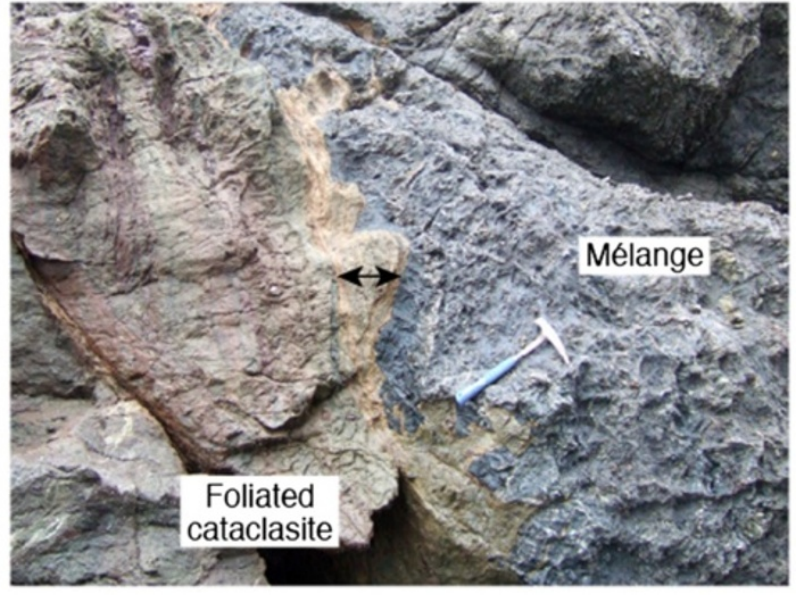

e

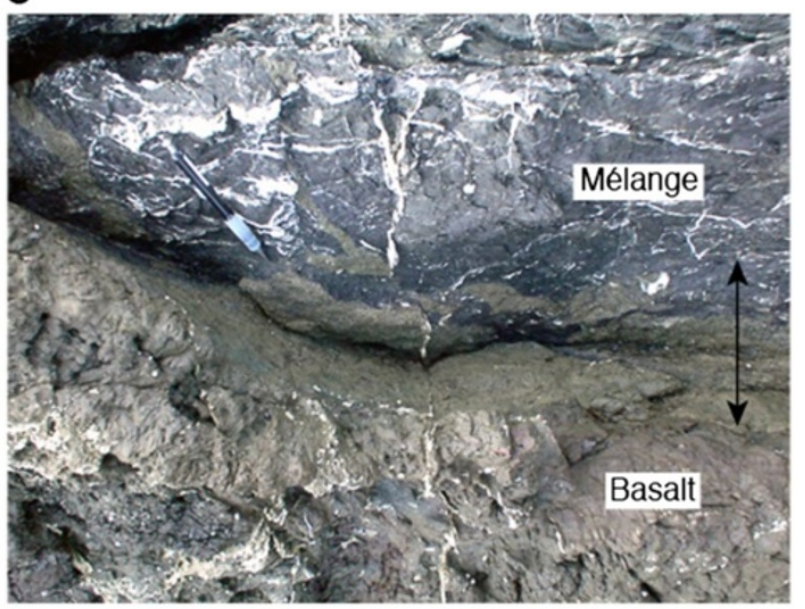

f

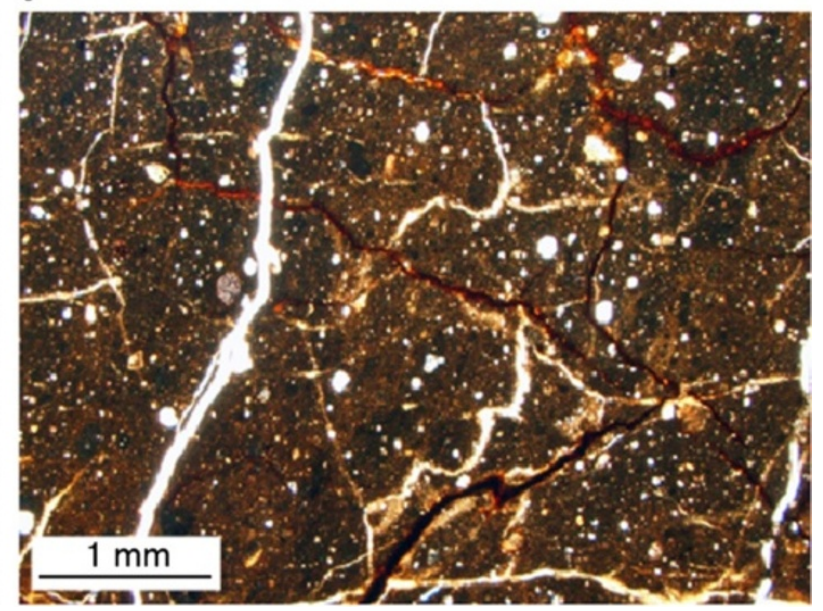

Figure 12 (See legend on next page.) 
(See figure on previous page.)

Figure 12 Macroscopic and microscopic occurrences of fluidized fault rocks. (a-c) Fluidized fault rocks from the Kodiak accretionary complex (modified from Brodsky et al. 2009; Meneghini et al. 2010). (d-f) Fluidized fault rocks from the Shimanto accretionary complex (modified from Ujiie et al. 2007a). (a) Flame-like intrusions of the black fault rock into the overlying cataclasite, and mixing flow between the black fault rock and the cataclasite. (b) Flow deformation developed in granular (Gr) and crystalline (Cy) microlayers (plane-polarized light). (c) Back-scattered electron image showing clasts of crystalline material (white arrow) in the granular (Gr) microlayer. (d) Injection of the basalt-derived comminuted material into the overlying mélange. Black double arrows indicate the ultracataclasite showing injection structures. (e) Zone of mixing flow between basalt- and mélange-derived comminuted materials (black double arrow). (f) Homogeneous texture typically observed in the slipping zone showing injection structures (plane-polarized light).

could reflect that fluidization homogenized the internal texture of the slipping zone (Figure 12f). The very similar grain size distribution between the tip and the root of the injection vein indicates that settlement of the coarser grains by gravity is unlikely to have occurred during the injection, suggesting a rapid injection of fluidized granular material during faulting (Ujiie et al. 2007a).

The fluidized rock and the basalt slice immediately below $(\leq 1 \mathrm{~m})$ the fluidized rock constitute the altered zone where the magnetic susceptibilities are 1 or 2 orders of magnitude lower than those of basalt and basalt-derived foliated cataclasite in the fault zone due to a loss of magnetite and maghemite, and where color changes from dark green/dark red to light green/light brown are observed due to increased amounts of alteration products such as chlorite, mixed-layer chlorite/smectite, corrensite, and calcite (Ujiie et al. 2007a; Kameda et al. 2011). In addition, calcite and laumontite veins are also concentrated in and around the altered zone, showing a mutually crosscutting relationship between veins and the fluidized zone. These features suggest that fluidization occurred under fluid-infiltrated conditions.

The fluidized rock in the underplated basalt preserves evidence for frictional heating (Ujiie et al. 2008; Kameda et al. 2011). Fluid inclusions trapped in calcite can reequilibrate and increase in volume (i.e., stretching) when heated to temperatures higher than those of the initial entrapment at the entrapment pressure, resulting in an increase in homogenization temperatures (Roedder 1984). Ujiie et al. (2008) examined a distribution of homogenization temperatures across fluidized rock and revealed that the asymmetric, skewed frequency distributions of the homogenization temperatures due to stretching of fluid inclusions in calcite only occur in the fluidized rock; this feature was absent in the surrounding rocks including the altered basalt immediately below the fluidized rock (Figure 13a). Based on rapid overheating experiments on fluid inclusions in calcite, those authors also showed that histograms of homogenization temperatures from the fluidized rocks could be reproduced by a $50^{\circ} \mathrm{C}$ to $150^{\circ} \mathrm{C}$ temperature rise along the fluidized rock with respect to the ambient temperatures of $130^{\circ} \mathrm{C}$ to $150^{\circ} \mathrm{C}$.
Kameda et al. (2011) examined the clay mineralogy across the fluidized rock where the stretching of fluid inclusions in calcite due to frictional heating was detected by Ujiie et al. (2008). They found that the fluidized rock shows a markedly higher chlorite content in the mixed-layer chlorite/smectite with respect to the surrounding rocks (Figure 13b), which cannot be explained by hydrothermal alteration or regional very low grade metamorphism, but is consistent with frictional heating associated with localized slip. The estimated temperatures during the increased heating determined from chlorite geothermometry and the presence of small quantities of corrensite range from $185^{\circ} \mathrm{C}$ to $260^{\circ} \mathrm{C}$ (Kameda et al. 2011). This suggests that the temperature rise during frictional heating is in the range of $35^{\circ} \mathrm{C}$ to $150^{\circ} \mathrm{C}$, consistent with that determined from the stretching of fluid inclusions in calcite. Fluidization requires a reduction of normal stress on the fault, and several driving mechanisms have been proposed for fluidization in faults, including strong, short-wavelength and normal interface vibrations (Brune et al. 1993; Melosh 1996) and fluid pressurization and reduction of effective normal stress due to frictional heating (i.e., thermal pressurization) (Sibson, 1973; Rice 2006). Theoretical models of thermal pressurization suggest that the temperature rise is $<200^{\circ} \mathrm{C}$ when pore dilation and loss of heat and fluid are negligible during seismic slip (e.g., Lachenbruch 1980; Mase and Smith 1987). Therefore, fluidization at a small temperature rise of less than $150^{\circ} \mathrm{C}$ under fluid-infiltrated conditions most likely occurred under thermal pressurization.

Effects of fluidization on earthquake faulting Compared to a grain friction regime in which grain friction and comminution are the dominant deformation mechanisms, fluidization in a grain-inertia regime is expected to reduce the shear strength of faults. In fact, high-velocity $(1.3 \mathrm{~m} / \mathrm{s})$ friction experiments on natural fault gouges successively reproduced fluidization-related microstructures found in nature, during which the apparent coefficient of friction (ratio of shear to normal stress) decreased to approximately 0.1 to 0.2 (Mizoguchi et al. 2009; Kitajima et al. 2010; Ujiie and Tsutsumi 2010).

Mizoguchi et al. (2009) reported folding and fluttering structures in the gouge after high-velocity friction 


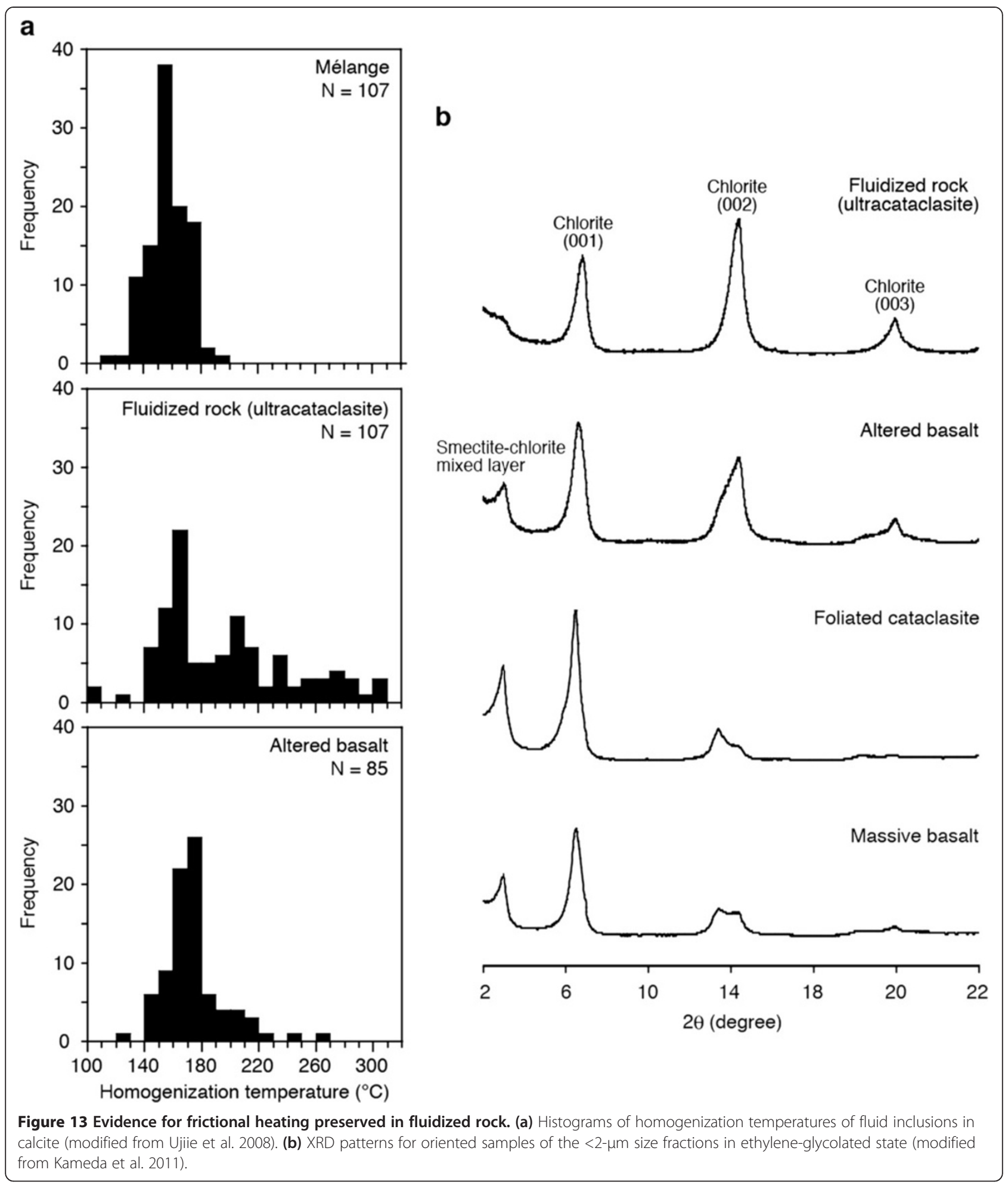

experiments under dry (room humidity) conditions. Such microstructures suggest that the Reynolds number was large enough for the generation of turbulent flow, possibly due to a decrease in viscosity and/or an increase in the effect of inertial flow.
Ujiie and Tsutsumi (2010) demonstrated that the steadystate shear stress at high slip rate is almost independent of normal stress under wet (water-saturated) conditions, with the resultant microstructure showing grain size segregation associated with granular collision in the fluidized flow 
(Figure 14). A similar microstructure was reported from the fault gouge that is interpreted to be the principal slip zone during the 1999 Chi-Chi earthquake in Taiwan (Boullier et al. 2009). The dispersive pressure $(P)$ related to granular collision in the fluidized flow is proportional to the square of the shear rate $(d y / d t)$ (Bagnold 1954; Hanes and Inman 1985):

$$
P \propto \rho(\lambda D)^{2}\left(\frac{d \gamma}{d t}\right)^{2} \approx \rho(\lambda D)^{2}\left(\frac{V}{w}\right)^{2}
$$

where $\rho$ is the density of the granular fluid materials, $\lambda$ is the linear grain concentration defined by the ratio of the grain diameter to the mean free separation distance between the grains, $D$ is the grain diameter, $V$ is the slip rate, and $w$ is the thickness of the slip zone. Equation 8 indicates that the difference in $P$ between the large and small grains is greater at high $V$, which results in the formation of voids around the larger grains. Small grains have a higher probability of filling these voids than the larger ones do, and so the larger grains migrate upwards as the smaller grains fill the voids through downward movement under the influence of gravity. Such grain size segregation is comparable to the Brazil-nut effect: when grain mixtures are shaken or collided, the larger grains rise to the top, whereas smaller grains move downwards under gravity (Rosato et al. 1987; Breu et al. 2003). Grain size segregation is observed in the gouge sheared at slip rates of $\geq 0.62 \mathrm{~m} / \mathrm{s}$, possibly reflecting the fact that the Brazil-nut effect is caused by the large difference in $P$ between the large and the small grains at high $V$ (Ujiie and Tsutsumi 2010). These experimental and microstructural features suggest that the gouge behaved like a fluid during fluidization at high slip rates. As the shear stress of gouge exhibiting fluid-like behavior is nearly independent of the normal stress, the apparent coefficient

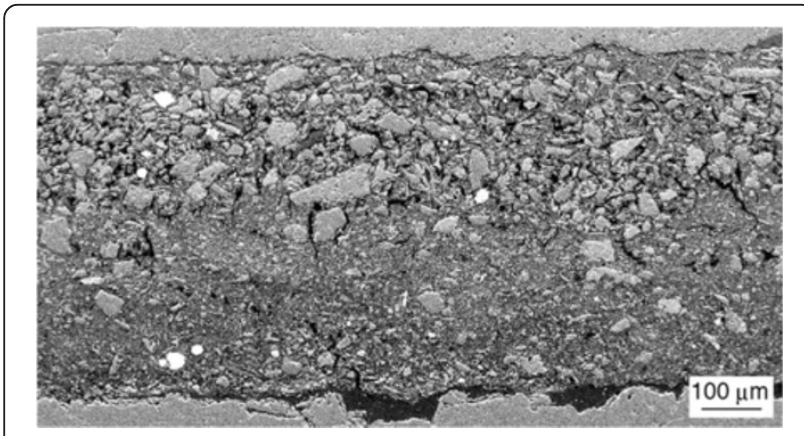

Figure 14 Grain size segregation seen in the gouge after high-velocity friction experiments under wet conditions. This microstructure is absent at low slip rates and is potentially a new microstructural indicator of fluidization at high shear rates (back-scattered electron image). of friction would be very low, particularly at larger normal stresses.

Analysis of the geometry of intrusive structures may be useful in estimating the shear resistance during earthquake faulting. As shown in Figure 12a, cusped intrusions extending upward from the black fault rock could represent gravitational (Rayleigh-Taylor) instability that occurs when a lower density layer is overlain by a higher density layer, and the denser layer flows to accommodate intrusions from the less dense layer (Allen 1985). Brodsky et al. (2009) measured both the spacing of intrusions and the density of layered materials, and then conducted a linear stability analysis using the fluid dynamics of the RayleighTaylor instability. Their results show that the spacing between intrusions is best explained by a moderately inertial flow with fluid velocities in the order of $0.1 \mathrm{~m} / \mathrm{s}$. The viscosity determined from the Reynolds number of the buoyant flow is less than $1 \mathrm{~Pa} \mathrm{~s}$, which requires a very low shear resistance of less than $20 \mathrm{~Pa}$ (Brodsky et al. 2009).

There are limited studies on dynamic processes occurring during fluidization in faults. However, all results currently available suggest that the fault was lubricated due to fluidization.

\section{Fluid-rock interactions in fault zones}

Fault zones in exhumed accretionary complexes record fluid-rock interaction processes, many of which are interpreted in terms of a seismic cycle or coseismic fluid-rock interactions (Okamoto et al. 2006; Meneghini and Moore 2007; Ujiie et al. 2007a; Ishikawa et al. 2008; Hamada et al. 2011; Yamaguchi et al. 2011a, 2012; Kimura et al. 2013).

The Taiwan Chelungpu Fault Drilling Project successfully recovered the fault zone associated with the Chi-Chi earthquake, for which a large coseismic displacement of approximately $8.3 \mathrm{~m}$ was recorded near the drill sites (Ma et al. 2006). Ishikawa et al. (2008) analyzed the trace element concentrations and isotope ratios across the active Chelungpu Fault. The results show that there are marked enrichments of $\mathrm{Sr}$; depletions in $\mathrm{Li}, \mathrm{Rb}$, and Cs; and a decrease of strontium isotope in the 2- to 15$\mathrm{cm}$-thick fault gouges (Figure 15). Indeed, one of gouges at a depth of $1,136 \mathrm{~m}$ is very likely to have slipped during the Chi-Chi earthquake (Ma et al. 2006). Model calculations reveal that the observed patterns of fluid-mobile trace elements and isotope ratios in the gouges are well reproduced when solid-fluid interactions occur at temperatures higher than $350^{\circ} \mathrm{C}$. Abrupt changes of fluid-mobile elements and of strontium isotopes in the gouges are suggested to represent the interaction of high-temperature pore fluid and gouge materials during earthquake faulting (Ishikawa et al. 2008). A very similar feature was found in the 5- to 10-mm-thick slip zone in the thrust of the Emi Group, Boso Peninsula, Japan, where the accretionary 


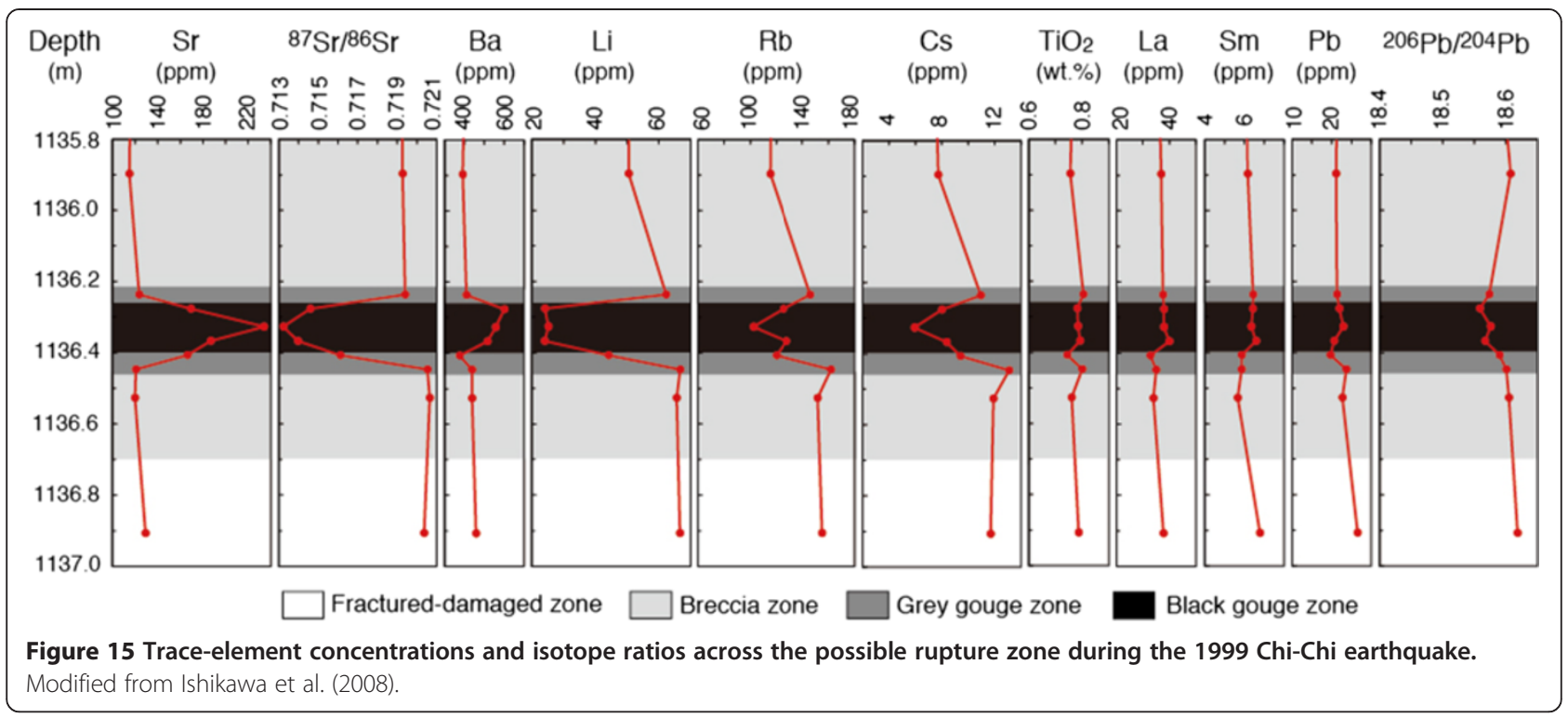

prism has been exhumed from 1- to 4-km depth following the arc-arc collision in central Japan (Hamada et al. 2011). These studies demonstrate that fluid-mobile trace elements and isotope ratios are useful tools for the detection of the recent and past coseismic presence of high-temperature fluid $\left(>350^{\circ} \mathrm{C}\right)$ in the slip zones.

The Rodeo Cove thrust in the Marine Headlands terrane, Franciscan complex, which imbricates basaltchert-sandstone sequences, is considered to have been formed by a duplex underplating at depths of 8 to $10 \mathrm{~km}$ and temperatures of $200^{\circ} \mathrm{C}$ to $250^{\circ} \mathrm{C}$ (Meneghini and Moore 2007). Thrust-related deformations mainly occur along the basalt, which shows repeated brittle shear, carbonate-filled vein formation, and pressure solution. The veins are oriented parallel to foliations that formed in association with brittle shear and pressure solution, which can be explained by either a switching of the principal stress orientations between the intervals of veining and the pressure solution, or a fixed stress orientation with a difference in tensional strength parallel to and perpendicular to the foliation. In either case, very high fluid pressure is required. Meneghini and Moore (2007) interpreted the veining as representing an immediately post-seismic fluid pressure drop and consequent carbonate precipitation, while shear- and pressure solution-related foliations reflect slow interseismic deformations.

The underplating-related thrust in the Late Cretaceous to early Tertiary Shimanto accretionary complex of eastern Shikoku, which imbricates basalt-mélange sequences (Figure 8), shows different aspects of veining (Ujiie et al. 2007a; Yamaguchi et al. 2012). Here, both network and fault-filled veins are recognized (Yamaguchi et al. 2012). Network veins develop in the mélange adjacent to the basalt-derived ultracataclasite that records fluidization, and many are extensional veins that are oriented perpendicular to the thrust. The vein-filling minerals are primarily calcite and secondarily laumontite/ quartz. In some cases, the network veins show a mutually crosscutting relationship with the ultracataclasite, and in other cases, the mélange, in which the network veins are intensely developed, is fragmented and incorporated into the basalt-derived foliated cataclasite. These features indicate repeated episodes of faulting and veining. The orientation of extension veins suggests that $\sigma_{1}$ was perpendicular to the thrust between faulting episodes, suggesting the presence of a weak fault due to fluid pressurization. The fault-filling veins are restricted to the gently dipping segment of the thrust with a length shorter than a few tens of meters. This type of vein is marked by angular to subangular fragments of ultracataclasites and altered basalts in calcite matrix. The non-planar geometry of the thrust and the spatial distribution and textural features of fault-filling veins are suggested to represent implosion brecciation (Sibson 1986), which could occur in association with a rapid depressurization at dilatant jogs in a thrust system during earthquake faulting (Ujiie et al. 2007a; Yamaguchi et al. 2012). Yamaguchi et al. (2012) revealed that the rare earth element patterns are different between the two vein types; while the source fluid of network veins was affected by a sorption process, that of fault-filling veins was affected neither by sorption nor by complexation processes. This suggests a temporal change in the physico-chemical behavior of the fluid along the thrust, which may occur in response to a seismic cycle.

Possible implosion breccia was also reported from the subsidiary fault in the hanging wall of the major out-ofsequence thrust (Nobeoka Thrust) in the Cretaceous- 
Tertiary Shimanto accretionary complex of eastern Kyushu (Okamoto et al. 2006; Kimura et al. 2013). The results of fluid-inclusion microthermobarometry indicate that the Nobeoka Thrust was active at temperatures of $180^{\circ} \mathrm{C}$ to $300^{\circ} \mathrm{C}$ and fluid pressures of 140 to $250 \mathrm{MPa}$, which may be analogous to the deeper part of the megasplay fault in the Nankai Trough (Kondo et al. 2005) (Figure 8). The breccia is marked by fragments of host rock (phyllite) in the carbonate matrix and is found in dilational jogs (or releasing bends along the undulatory fault plane) of less than a few tens of centimeters in length. The 1-mm-thick pseudotachylyte, found along the fault, cuts the breccias. Okamoto et al. (2006) and Kimura et al. (2013) interpreted the breccias as representing implosion brecciation at dilational jogs, while the pseudotachylyte resulted from frictional melting under relatively high effective normal stress after depressurization.

The fault zone associated with the Nobeoka Thrust contains mutually crosscutting faults and extension veins. Yamaguchi et al. (2011a) conducted major element mapping and trace element analyses of these veins and found a temporal change in fluid redox state. Here, quartz-calcite extension veins were derived from relatively oxidized fluids, while ankerite fault veins with a positive europium anomaly originated from relatively reduced fluids. Such a temporal change in fluid redox state may be linked to the seismic cycle (Yamaguchi et al. 2011a). Relatively oxidized fluids likely induced hydraulic fracturing at the pre-failure stage, resulting in the formation of extension veins. In contrast, the relatively reduced fluids precipitated along the faults at the immediate post-failure stage, which could have been caused by the advection of an exotic reducing fluid from serpentinized mantle peridotites or by the generation of hydrogen from coseismic mechanochemical reactions.

\section{Geological and experimental aspects of slow earthquakes} Studies using seismic reflection, ocean bottom seismometers, and seismic tomography suggest that the source regions of low-frequency seismic events correspond to zones of elevated fluid pressure, suggesting a very low stress drop during these events (Ito and Obara 2006b; Shelly et al. 2006; Matsubara et al. 2009; Kitajima and Saffer 2012). Low-frequency tremors and earthquakes at depths of 30 to $45 \mathrm{~km}$ and temperatures of $400^{\circ} \mathrm{C}$ to $550^{\circ} \mathrm{C}$ under increased fluid pressures are generally assumed to result from dehydration of the subducting oceanic plate (Obara 2002; Shelly et al. 2006; Matsubara et al. 2009). However, the geological aspects and physical mechanisms controlling slow earthquakes remain elusive (Schwartz and Rokosky 2007). Recently, geological records of slow earthquakes were examined in accretionary complexes that were exhumed from hypocentral depths and temperatures of slow earthquakes (Fagereng et al. 2011;
Hayman and Lavier 2014). In addition, experimental investigations of slow earthquakes have been conducted using possible representative rocks from their hypocentral regions (Burlini et al. 2009; Katayama et al. 2012; Ikari et al. 2013; Saito et al. 2013).

The Triassic accretionary mélange in the Chrystalls Beach Complex, South Island, New Zealand is considered to have formed during subduction at pumpellyiteactinolite facies metamorphic conditions at temperatures of $220^{\circ} \mathrm{C}$ to $350^{\circ} \mathrm{C}$ (Fagereng and Sibson 2010). In this mélange, the shear and extension veins developed contemporaneously, and the shear veins developed at angles subperpendicular to $\sigma_{1}$, consistent with shear slip at elevated fluid pressure during subduction (Fagereng et al. 2010). The shear veins are subparallel to cleavage in the mudstone matrix and are marked by incrementally developed quartz slickenfibers (Figure 16). Fagereng et al. (2011) revealed shear slip increments of 10 to $100 \mu \mathrm{m}$ based on measurements of inclusion band spacing. The quartz-coated shear surfaces are traceable for meters to tens of meters; thus, the ratio of slip to potential rupture length (i.e., $u / L$ ) is in the range of $10^{-6}$ to $10^{-5}$. Considering $u / L=\Delta \tau / G$ (Wells and Coppersmith 1994), where $\Delta \tau$ is the stress drop and $G$ is the shear modulus for subducting sediments ( $3 \mathrm{GPa}), \Delta \tau$ can be estimated in the range of 3 to $30 \mathrm{kPa}$ (Fagereng et al. 2011). It is likely that the tectonic setting of the mélange and the very low stress drop during a single shear slip event are comparable to the low-frequency earthquakes observed in swarms during episodic tremors and slow slip events along subduction thrusts. Thus, shear veins with incrementally developed slickenfibers (Figure 16) may be a product of tremor and slow slip (Fagereng et al. 2011).

Saito et al. (2013) examined the fault rocks and frictional properties of thrusts in the Eocene Kayo Formation in the Shimanto accretionary complex of Okinawa Island, Ryukyu Arc. The Kayo Formation consists of coherent turbidites that were scraped off and accreted to the overriding plate by subduction of the young oceanic plate, during which folds and thrusts were buried at depths of 5 to $6 \mathrm{~km}$ (Ujiie 1997). The geological setting of the Kayo Formation is comparable to that of shallow very low frequency earthquakes (VLFE) in accretionary prisms (Ito and Obara 2006a; Ando et al. 2012; Sugioka et al. 2012). Two types of deformations are recognized in thrusts: a localized slip along the quartz-coated discrete slip surface and a distributed shear along clay foliations. The frictional velocity dependence of thrust materials indicates that quartz-rich thrust material shows velocity weakening at 0.0028 to $0.28 \mathrm{~mm} / \mathrm{s}$ but velocity strengthening at 0.28 to $2.8 \mathrm{~mm} / \mathrm{s}$, which is favorable for the occurrence of VLFE. In contrast, the thrust material with clay foliations only exhibits velocity strengthening at 0.0028 to $2.8 \mathrm{~mm} / \mathrm{s}$. These data suggest that the 


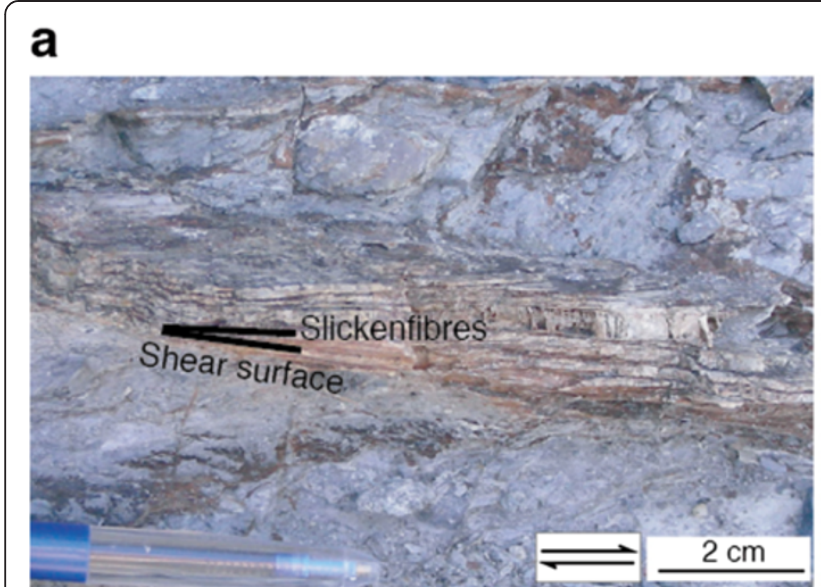

\section{b}

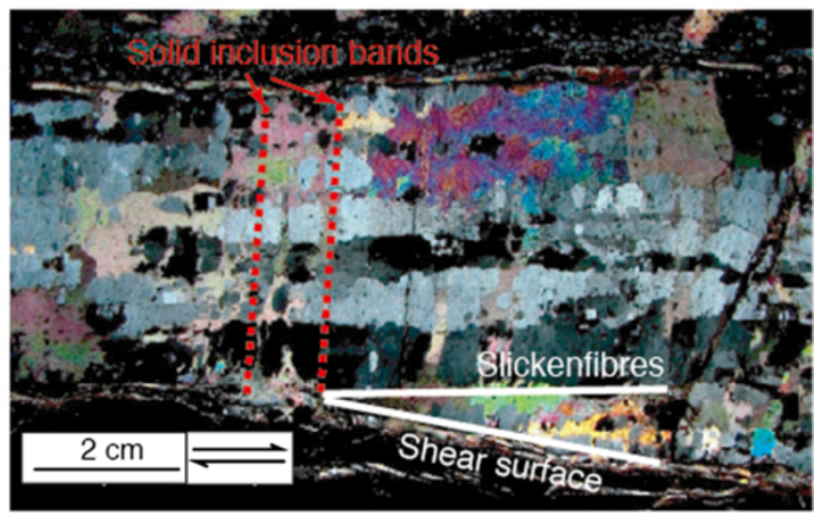

C
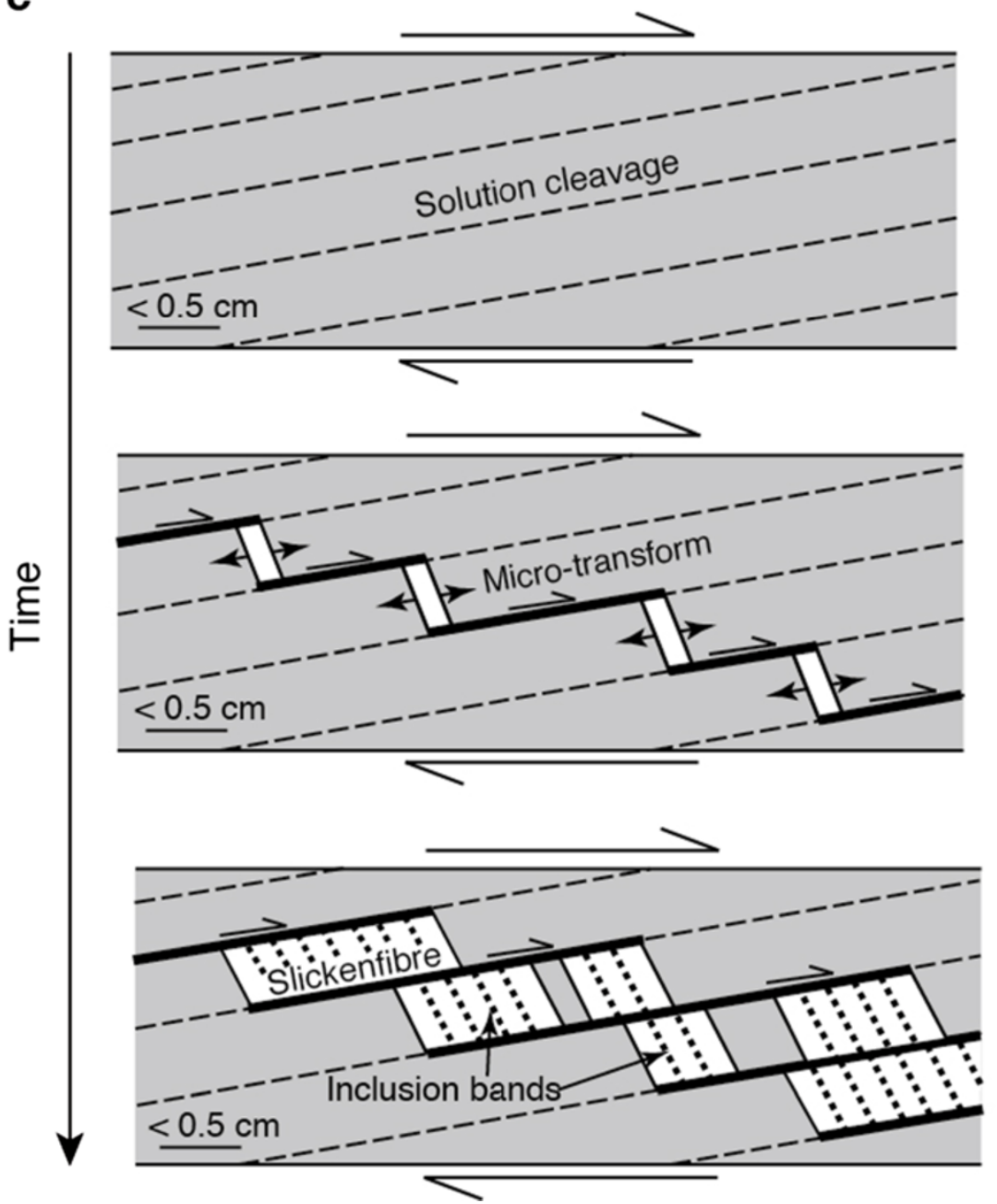

Figure 16 Shear veins developed in the mélange (modified from Fagereng et al. 2010). Pairs of half arrows indicate sense of shear. (a) Mesoscopic appearance of a shear vein with slickenfibers. (b) Microscopic appearance of a shear vein cut parallel to the slickenfibers and perpendicular to the shear surface, showing the small angle between the slickenfibers and the vein margin, and the solid inclusion bands subperpendicular to the slickenfibers (cross-polarized light). (c) Schematic diagram showing incremental growth of slickenfibers. 
occurrence and spatial distribution of VLFE may be controlled by the quartz content and development of clay foliations along thrusts. Quartz-rich thrusts derived from sandy turbidites (quartzose arenite) and quartzcoated slip surfaces (or quartz fibrous shear veins) are potential sources of VLFE, whereas foliated thrust materials are frictionally stable, thereby arresting the generation of VLFE (Saito et al. 2013).

On the basis of friction experiments on brecciated hemipelagic silty claystone taken from shallow portions of the megasplay fault and the plate-boundary thrust in the Nankai subduction zone, Ikari et al. (2013) proposed that slip-weakening behavior may be a viable mechanism for the generation of VLFE, rather than velocity-weakening behavior. They measured the slip dependence of friction and the change in friction associated with velocity steps in the range of 0.03 to $100 \mu \mathrm{m} / \mathrm{s}$. Although all samples showed velocity strengthening, the effect of slip weakening overcomes the initial velocity-strengthening behavior, with this effect being greatest in the velocity range of 0.3 to $3 \mu \mathrm{m} / \mathrm{s}$. The maximum effect of slip weakening in this velocity range can facilitate slip acceleration, but the effect of velocity-strengthening behavior becomes dominant at high slip velocities, which likely generates slow slip events or VLFE. Ikari et al. (2013) also reported that nucleation patch sizes estimated from physical property measurements on the Nankai samples are comparable to those expected for the VLFE in the Nankai subduction zone.

Katayama et al. (2012) shed light on the inferred fluid overpressure in regions of episodic tremor and slip (ETS) at depths of around $30 \mathrm{~km}$. Hydrous minerals in subducting oceanic plates release water into the overlying mantle wedge due to dehydration reactions, resulting in serpentinization at the plate interface. The serpentinite has a strong foliation associated with the preferred orientation of highly anisotropic minerals parallel to the plate interface (Katayama et al. 2009). Kawano et al. (2011) demonstrated that fluid flow parallel to serpentinite foliation is at least 1 order of magnitude faster than that perpendicular to foliation based on permeability measurements. It is likely that this permeability anisotropy of serpentinite induces preferential fluid migration along the subducting plate interface. However, migrating fluid could become trapped at the Moho, because the gabbro in the lower crust is 2 orders of magnitude less permeable than the serpentinite in the underlying mantle (Katayama et al. 2012). This could lead to an increase in fluid pressure at the corner of the mantle wedge that overlies the subducting plate, thereby triggering ETS at a depth of about $30 \mathrm{~km}$. Katayama et al. (2012) proposed that slow earthquakes under elevated fluid pressure are likely to occur when the velocity of upward fluid migration is faster than the subduction velocity, potentially causing regional variations in lowfrequency seismic events.

The generation of seismic tremor was confirmed from dehydration experiments on serpentinite (Burlini et al. 2009). The experiments were conducted in a Paterson apparatus at isostatic stresses of 200 or $320 \mathrm{MPa}$ and temperatures up to $1,000^{\circ} \mathrm{C}$, during which the acoustic emission (AE) output was recorded by piezoelectric transducers. The results show that tremor and swarms of AEs were generated when the expulsion of water occurred from the dehydration of serpentinite (the timing of dehydration was detected by transient sample cooling due to the endothermic dehydration reaction of serpentinite). Seismic signals in the form of AEs are closely similar to those in natural tremor, and frequency scaling can be established between experimental and natural tremors (Burlini et al. 2009). Dehydration of serpentinite, the typical rock of a subducting oceanic mantle, is expected to occur at the temperatures in the hypocentral region of ETS, which is located in the transition zone between the locked section of the subduction thrust and the aseismically/plastically deforming zone (Obara 2002; Shelly et al. 2006; Matsubara et al. 2009). The experiments demonstrated that dehydration triggers tremor, even in the absence of an external differential stress. Dehydration-derived water may increase the fluid pressure and makes the transition zone highly unstable under a small differential stress, which could trigger ETS and resultant increase in stress acting on the locked section (Burlini et al. 2009).

\section{Conclusions}

We have reviewed recent advances in the study of fault rocks in accretionary prisms. Compared to other tectonic settings (for example fault zones in the continental crust, as recently reviewed by Faulkner et al. 2010), studies of fault rocks in subduction zones are still immature. Studies of the physical and chemical processes that occur during subduction earthquakes also remain in their infancy (see the detailed review of earthquake physics and chemistry based on the integrated field and laboratory approach by Niemeijer et al. 2012). Nevertheless, in the last decade, our understanding of earthquake faulting in subduction zones has greatly improved through fault rock studies in accretionary prisms. These new insights gained into earthquake faulting in subduction zones are summarized below.

The major result from fault rock studies stemming from the NanTroSEIZE project is the detection of past frictional heating along 2- to 10-mm-thick, dark, clay-rich fault gouges of the megasplay fault and the plate-boundary thrust, even at shallow depths ( $<450 \mathrm{mbsf})$. High-velocity friction experiments and permeability measurements conducted on fault zone materials have demonstrated that 
earthquake rupture propagates easily through clay-rich fault gouge by dynamic weakening at high slip rates (e.g., thermal pressurization). On the other hand, the clay-rich materials commonly exhibit velocity-strengthening behavior at low slip rates. The NanTroSEIZE project has clarified that once high-velocity weakening mechanisms begin to operate, the propagation of seismic slip could occur even in initially velocity-strengthening materials at shallow depths (Figure 17). This fault behavior would therefore enhance tsunami generation during subduction earthquakes.

Propagation of seismic slip along velocity-strengthening materials may also occur at deeper depths in subduction zones. Pseudotachylytes in the Shimanto accretionary complex are derived from frictional melting of illite-rich slip zones that commonly show velocity-strengthening behavior at low slip rates (Saffer and Marone 2003), although some low-velocity friction experiments on illite gouge exhibit stick-slip behavior (Moore et al. 1989). The estimated viscosity and shear resistance during frictional melting are very low, suggesting the enhancement of earthquake rupture propagation due to melt lubrication. However, high-velocity friction experiments on the host rock of pseudotachylytes (argillite) suggest that viscous braking associated with the dehydration increasing viscosity of the melt layer could occur at shallow depths. If frictional melting is a dominant coseismic deformation mechanism along the fault in a subduction zone, then the transition from melt lubrication at deep depths to viscous braking at shallow depths may be one of the factors controlling the updip limit of the earthquake rupture zone. An important implication of this is that the updip limit of the earthquake rupture zone should be viewed in terms of dynamic processes that operate at high slip rates, rather than the change from velocity-weakening to velocitystrengthening frictional behavior (Figure 17).

A further discovery made using fault rock studies in the exhumed accretionary complexes is the fluidized rocks within or along the margin of the tectonic mélanges, which are thought to represent paleo-subduction thrusts. The fluidized rock-bearing fault zones commonly record fluid-related phenomenon, and some of fluidized rocks preserve evidence for a small temperature rise of less than $150^{\circ} \mathrm{C}$ associated with frictional heating. These features suggest that fluidization may be caused by the restraint of a temperature rise by thermal pressurization. In the Shimanto accretionary complex, the thickness of the fluidized zones is typically a few centimeters, which is 1 order of magnitude thicker than that of molten zones. In contrast to frictional melting, it is probable that fluid does not escape from the slipping zone during earthquake faulting, which results in thermal pressurization-induced fluidization. In addition to transport properties such as permeability, the thickness of the seismic slip zone appears

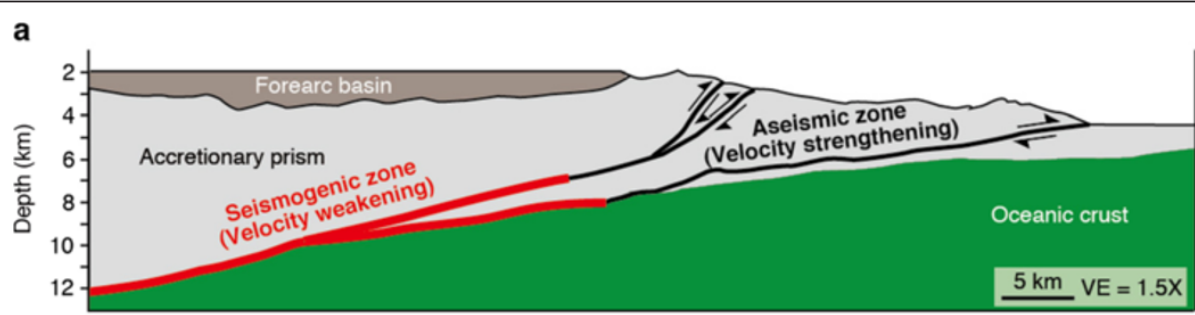

b

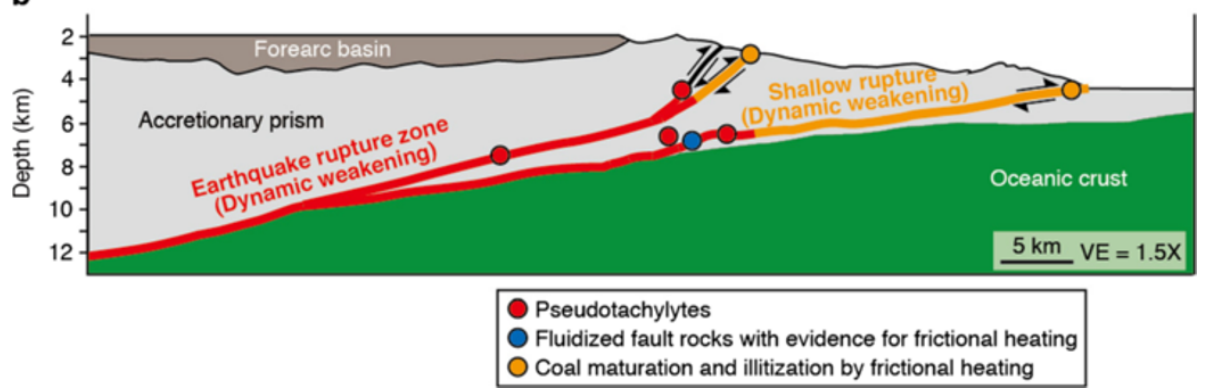

Figure 17 Concept of earthquake faulting in subduction zones shown in schematic profile of the Nankai accretionary prism. (a) Previous view of seismogenic zone. Seismogenic zone shows velocity-weakening frictional behavior, whereas aseismic zone exhibits velocity-strengthening frictional behavior. (b) Improved view of earthquake faulting in subduction zones after fault rock studies in the NanTroSEIZE and the Shimanto accretionary complex. Fault segments showing velocity-strengthening behavior at low slip rates could be weakened as a result of dynamic weakening. This could occur at various depths in the subduction zone, in some cases resulting in shallow slip. In this conceptual model, the updip limit of the earthquake rupture zone corresponds to the location where dynamic weakening is no longer effective. Possible causes of earthquake rupture termination include viscous braking due to an increase in melt viscosity and ineffective thermal pressurization/fluidization due to increased effective normal stress associated with decreased fluid pressure. 
to be an important factor controlling coseismic deformation mechanisms. The estimated viscosity and apparent coefficient of friction (or shear stress) during fluidization are very low, showing that fluidization is also a dynamic weakening mechanism of faults during subduction earthquakes.

The fluid-rock interaction recorded in fault zones of exhumed accretionary complexes has been mostly interpreted in terms of a seismic cycle or coseismic fluid-rock interactions. Geological and experimental investigations of subduction zone rocks suggest that fluid plays a key role in slow slip processes in subduction zones, which is consistent with the results of geophysical measurements. However, there has been limited research in this area, and future study is required to examine the frictional properties of various lithologies in subduction zones. On-land accretionary complexes and metamorphic rocks exhumed from source depths of slow earthquakes are expected to record the slow slip processes in subduction zones. Future geological studies are required to shed light on slow earthquakes.

Finally, multi-disciplinary and integrated approaches are crucial to gain a better understanding of the dynamics and physico-chemical processes operating during earthquakes in subduction zones. They include investigations of fault rocks in accretionary prisms, laboratory experiments using subduction zone materials, numerical modeling incorporating the results of fault rock studies and laboratory measurements, geophysical surveys in subduction zones, and sampling and monitoring of active fault zones by deep-ocean drilling. In particular, geophysical surveys and deep-ocean drilling are considered the most promising and only avenues for investigating earthquake processes in non-accreted, erosive margins.

\section{Abbreviations}

ETS: episodic tremor and slip; IODP: Integrated Ocean Drilling Program; mbsf: meters below sea floor; NanTroSEIZE: Nankai Trough Seismogenic Zone Experiment; VLFE: very-low-frequency earthquakes.

\section{Competing interests}

The authors declare that they have no competing interests.

\section{Authors' contributions}

$\mathrm{KU}$ and GK wrote the manuscript and prepared the figures. KU carried out the experimental and microstructural studies. Both authors read and approved the final manuscript.

\footnotetext{
Acknowledgements

We would like to thank all of our collaborators for their insightful and thoughtful discussions. The members of the 'IODP NanTroSEIZE Expedition 316 fault rock team' (Frederick Chester, Daniel Curewitz, Olivier Fabbri, David Goldsby, Chun-Feng Li, Arito Sakaguchi, Akito Tsutsumi, and Asuka Yamaguchi) greatly contributed to the shipboard data collection and post-cruise sample treatment and measurement presented here. We would like to give special thanks to Akito Tsutsumi, Asuka Yamaguchi, Arito Sakaguchi, Yuri Fialko, Jun Kameda, Yoshitaka Hashimoto, Haruka Yamaguchi, and Shoichi Toh for their collaborative research in the field and laboratory. We owe thanks to Arito Sakaguchi and Asuka Yamaguchi for providing original graphics in Figures 6 and 7, respectively; to Francesca Meneghini for original photomicrographs
}

in Figures 10f, 12b, and c; Christie Rowe for an original outcrop photo in Figure 12a; Jun Kameda and Tsuyoshi Ishikawa for original graphics in Figures $13 \mathrm{~b}$ and 15 , respectively; and to Ake Fagereng for original photos and graphics in Figure 16. We thank two anonymous reviewers, Francesca Meneghini, and Casey Moore for their helpful comments and editing. This research was funded by the Ministry of Education, Culture, Sports, Science and Technology of Japan through grant no. 21107005.

\section{Author details}

1 Graduate School of Life and Environmental Sciences, University of Tsukuba, 1-1-1 Tennodai, Tsukuba 305-0006, Japan. ${ }^{2}$ Research and Development Center for Ocean Drilling Science, Japan Agency for Marine-Earth Science and Technology, 2-15 Natsushima-cho, Yokosuka 237-0061, Japan. ${ }^{3}$ Department of Earth and Planetary Science, The University of Tokyo, 7-3-1 Hongo, Bunkyo-ku, Tokyo 113-0033, Japan.

Received: 29 November 2013 Accepted: 6 April 2014 Published: 9 May 2014

\section{References}

Allen AR (1979) Mechanism of frictional fusion in fault zones. J Struct Geol $1: 231-243$

Allen JRL (1985) Principles of physical sedimentology. George Allen and Unwin, Boston

Ando M, Tu Y, Kumagai H, Yamanaka Y, Lin C-H (2012) Very low frequency earthquakes along the Ryukyu subduction zone. Geophys Res Lett doi:10.1029/2011GL050559

Bagnold RA (1954) Experiments on a gravity-free dispersion of large solid spheres in a Newtonian fluid under shear. Proc R Soc London A 225:49-63, doi:10.1098/rspa.1954.0186

Boullier A-M, Yeh E-C, Boutareaud S, Song S-R, Tsai C-H (2009) Microscale anatomy of the 1999 Chi-Chi earthquake fault zone. Geochem Geophys Geosyst doi:10.1029/2008GC002252

Breu APJ, Ensner H-M, Kruelle CA, Rehberg I (2003) Reversing the Brazil-nut effect: competition between percolation and condensation. Phys Rev Lett doi:10.1103/PhysRevLett.90.014302

Brodsky EE, Rowe CD, Meneghini F, Moore JC (2009) A geological fingerprint of low-viscosity fault fluid mobilized during an earthquake. J Geophys Res do: 10.1029/2008JB005633

Brune JN, Brown S, Johnson PA (1993) Rupture mechanism and interface separation in foam rubber models of earthquakes: a possible solution to the heat flow paradox and the paradox of large overthrusts. Tectonophysics 218:59-67

Burlini L, Di Toro G, Meredith P (2009) Seismic tremor in subduction zones: rock physics evidence. Geophys Res Lett doi:10.1029/2009GL037735

Byrne T (1984) Early deformation in melange terranes of the Ghost Rocks Formation, Kodiak Islands, Alaska. Geol Soc Am 198:21-51

Casciello E, Cosgrove JW, Cesarano M, Romero E, Queralt I, Vergés J (2011) Illite-smectite patterns in sheared Pleistocene mudstones of the Southern Apennines and their implications regarding the process of illitization: a multiscale analysis. J Struct Geol 33:1699-1711, doi:10.1016/j.jsg.2011.08.002

Chester FM, Logan JM (1987) Composite planar fabric of gouge from the Punchbowl fault, California. J Struct Geol 9:621-634

Chester FM, Rowe C, Ujiie K, Kirkpatrick J, Regalla C, Remitti F, Moore JC, Toy V, Wolfson-Schwehr M, Bose S, Kameda J, More JJ, Brodsky EE, Equchi N, Toczko S (2013) Expedition 343 and 343T Scientists (2013) Structure and composition of the plate-boundary slip zone for the 2011 Tohoku-Oki earthquake. Science 342:1208-1211

Collettini C, Niemeijer A, Viti C, Smith SAF, Marone C (2011) Fault structure, frictional properties and mixed-mode fault slip behavior. Earth Planet Sci Lett 311:316-327, doi:10.1016/j.epsl.2011.09.020

Corrigan GM (1982) The crystal morphology of plagioclase feldspar produced during isothermal supercooling and constant rate experiments. Mineral Mag 46:433-439, doi:10.1180/minmag.1982.046.341.04

Deer WA, Howie RA, Zussman J (1992) An introduction to the rock-forming minerals. Green and Co Ltd, London Longmans

Dingwell DB, Webb SL (1989) Structural relaxation on silicate melts and nonNewtonian melt rheology in geologic processes. Phys Chem Miner 16:508-516

Dingwell DB, Bagdassarov NS, Bussod GY, Webb SL (1993) Magma rheology: experiments at high pressures and supplication to the Earth's mantle. Mineral Assoc Canada Short Course Handbook 21:233-333 
Di Toro G, Pennacchioni G (2004) Superheated friction-induced melts in zoned pseudotachylytes within the Adamello tonalities (Italian Southern Alps). J Struct Geol 26:1783-1801, doi:10.1016/j.jsg.2004.03.001

Di Toro G, Pennacchioni G, Teza G (2005) Can pseudotachylytes be used to infer earthquake source parameters? An example of limitations in the study of exhumed faults. Tectonophysics 402:3-2, doi:10.1016/j. tecto.2004.10.014

Di Toro G, Hirose T, Nielsen S, Shimamoto T (2006) Relating high-velocity rock-friction experiments to coseismic slip in the presence of melts. In: Abercrombie R (ed) Radiated energy and the physics of earthquake faulting, vol 170, Geophys Monogr Ser. AGU, Washington DC, pp 121-134

Fagereng A, Sibson RH (2010) Mélange rheology and seismic style. Geology 38:751-754, doi:10.1130/G30868.1

Fagereng A, Remitti F, Sibson RH (2010) Shear veins observed within anisotropic fabric at high angles to the maximum compressive stress. Nat Geosci 3:482-485, doi:10.1038/ngeo898

Fagereng A, Remitti F, Sibson RH (2011) Incrementally developed slickenfibersgeological record of repeating low stress-drop seismic events? Tectonophysics 510:381-386, doi:10.1016/j.tecto.2011.08.015

Faulkner DR, Jackson CAL, Lunn RJ, Schlische RW, Shipton ZK, Wibberley CAJ, Withjack MO (2010) A review of recent developments concerning the structure, mechanics and fluid flow properties of fault zones. J Struct Geol 32:1557-1575, doi:10.1016/j.jsg.2010.06.009

Faulkner DR, Mitchell TM, Behnsen J, Hirose T, Shimamoto T (2011) Struck in the mud? Earthquake nucleation and propagation through accretionary forearcs. Geophys Res Lett doi:10.1029/2011GL048552

Fialko Y, Khazan Y (2005) Fusion by earthquake fault friction: stick or slip? J Geophys Res doi:10.1029/2005JB003869

Fisher D, Byrne T (1987) Structural evolution of underthrusted sediments, Kodiak Island, Alaska. Tectonics 6:775-793

Fujiwara T, Kodaira S, No T, Kaiho Y, Takahashi N, Kaneda Y (2011) The 2011 Tohoku-Oki earthquake: displacement reaching the trench axis. Science 334:1240, doi:10.1126/science.1211554

Fulton PM, Harris RN (2012) Thermal considerations in inferring frictional heating from vitrinite reflectance and implications for shallow coseismic slip within the Nankai subduction zone. Earth Planet Sci Lett 335-336:206-215, doi:10.1016/j.epsl.2012.04.012

Fulton PM, Brodsky EE, Kano Y, Mori J, Chester F, Ishikawa T, Harris RN, Lin W, Eguchi N, Toczko S (2013) Expedition 343, 343T, and KR13-08 Scientists (2013) Low coseismic friction on the Tohoku-Oki fault determined from temperature measurements. Science 342:1214-1217, doi:10.1126/science.1243641

Furuichi H, Ujiie K, Sakaguchi A, Tsutsumi A (2013) What is the factor controlling the increase in vitrinite reflectance along faults? Paper presented at Japan Geoscience Union Meeting 2013. Makuhari, Chiba

Giordano D, Russell JK, Dingwell DB (2008) Viscosity of magmatic liquids: a model. Earth Planet Sci Lett 271:123-134, doi:10.1016/j.epsl.2008.03.038

Grim RE, Bradley WF (1940) Investigation of the effect of heat on the clay minerals illite and montmorillonite. J Am Ceram Soc 23:242-248

Hamada Y, Hirono T, Ishikawa T (2011) Coseismic frictional heating and fluid-rock interaction in a slip zone within a shallow accretionary prism and implications for earthquake slip behavior. J Geophys Res doi:10.1029/ 2010JB007730

Hanes DM, Inman DL (1985) Observations of rapidly flowing granular-fluid materials. J Fluid Mech 150:357-380

Hashimoto Y, Eida M, Kirikawa T, lida R, Takagi M, Furuya N, Nikaizo A, Kikuchi T, Yoshimitsu T (2012) Large amount of fluid migration around shallow seismogenic depth preserved in tectonic mélange: Yokonami mélange, the Cretaceous Shimanto Belt, Kochi, Southwest Japan. Is| Arc 21:53-64, doi:10.1111/j.1440-1738.2011.00806.x

Hayman NW, Lavier LL (2014) The geological record of deep episodic tremor and slip. Geology 42:195-198, doi:10.1130/G349990.1

Hirono T, Lin W, Yeh E-C, Soh W, Hashimoto Y, Sone H, Matsubayashi O, Aoike K, Ito H, Kinoshita M, Murayama M, Song S-R, Ma K-F, Hung J-H, Wang C-Y, Tsai Y-B (2006) High magnetic susceptibility of fault gouge within Taiwan Chelungpu fault: nondestructive continuous measurements of physical and chemical properties in fault rocks recovered from Hole B, TCDP. Geophys Res Lett doi:10.1029/2006GL026133

Hirono T, Fujimoto K, Yokoyama T, Hamada Y, Tanikawa W, Tadai O, Mishima T, Tanimizu M, Lin W, Soh W, Song S-R (2008) Clay mineral reactions caused by frictional heating during an earthquake: an example from the Taiwan Chelungpu fault. Geophys Res Lett doi:10.1029/2008GL034476
Hirono T, Ujiie K, Ishikawa T, Mishima T, Hamada Y, Tanimizu M, Soh W, Kinoshita $M$ (2009) Estimation of temperature rise in a shallow slip zone of the megasplay fault in the Nankai Trough. Tectonophysics 478:215-220

Hirose T, Shimamoto T (2005) Growth of molten zone as a mechanism of slip weakening of simulated faults in gabbro during frictional melting. J Geophys Res doi:10.1029/2004JB003207

Hyndman RD, Yamano M, Oleskevich DA (1997) The seismogenic zone of subduction thrust faults. Is| Arc 6:244-260, 10.1111/j.1440-1738.1997.tb00175.x

Ide S, Beroza GC, Shelly DR, Uchide T (2007) A scaling law for slow earthquakes. Nature 447:76-79, doi:10.1038/nature05780

Ide S, Baltay A, Beroza GC (2011) Shallow dynamic overshoot and energetic deep rupture in the $2011 M_{w} 9.0$ Tohoku-Oki earthquake. Science 332:1426-1429, 10.1126/science. 1207020

Ikari MJ, Saffer DM (2011) Comparison of frictional strength and velocity dependence between fault zones in the Nankai accretionary complex. Geochem Geophys Geosys doi:10.1029/2010GC003442

Ikari MJ, Saffer DM, Marone C (2007) Effect of hydration state on the frictional properties of montmorillonite-based fault gouge. J Geophys Res doi:10.1029/ 2006JB004748

Ikari MJ, Saffer DM, Marone C (2009) Frictional and hydrological properties of a major splay fault system, Nankai subduction zone. Geophys Res Lett doi:10.1029/2009GL040009

Ikari MJ, Marone C, Saffer DM (2011) On the relation between fault strength and frictional stability. Geology 39:83-86, doi:10.1130/G31416.1

Ikari MJ, Marone C, Saffer DM, Kopf AJ (2013) Slip weakening as a mechanism for slow earthquakes. Nat Geosci 6:468-472, doi:10.1038/ngeo1818

Ikesawa E, Sakaguchi A, Kimura G (2003) Pseudotachylyte from an ancient accretionary complex: evidence for melt generation during seismic slip along master décollement? Geology 31:637-640

Ikesawa E, Kimura G, Sato K, Ikehara-Ohmori K, Kitamura Y, Yamaguchi A, Ujiie K, Hashimoto $Y$ (2005) Tectonic incorporation of the upper part of oceanic crust to overriding plate of a convergent margin: an example from the Cretaceousearly Tertiary Mugi Mélange, the Shimanto Belt, Japan. Tectonophysics 401:217-230

Ishikawa T, Tanimizu M, Nagaishi K, Matsuoka J, Tadai O, Sakaguchi M, Hirono T, Mishima T, Tanikawa W, Lin W, Kikuta H, Soh W, Song S-R (2008) Coseismic fluid-rock interactions at high temperatures in the Chelungpu fault. Nat Geosci 1:679-683, doi:10.1038/ngeo308

Ito Y, Obara K (2006a) Dynamic deformation of the accretionary prism excites very low frequency earthquakes. Geophys Res Lett doi:10.1029/2005GL025270

Ito Y, Obara K (2006b) Very low frequency earthquakes within accretionary prisms are very low stress-drop earthquakes. Geophys Res Lett doi:10.1029/ 2006GL025883

Ito Y, Obara K, Shiomi K, Sekine S, Hirose H (2007) Slow earthquakes coincident with episodic tremors and slow slip events. Science 315:503-506, doi:10.1126/science.1134454

Kameda J, Ujiie K, Yamaguchi A, Kimura G (2011) Smectite to chlorite conversion by frictional heating along a subduction thrust. Earth Planet Sci Lett 305:161-170, doi:10.1016/j.epsl.2011.02.051

Katayama I, Hirauchi K, Michibayashi K, Ando J (2009) Trench-parallel anisotropy produced by serpentinite deformation in the hydrated mantle wedge. Nature 461:1114-1117, doi:10.1038/nature08513

Katayama I, Terada T, Okazaki K, Tanikawa W (2012) Episodic tremor and slow slip potentially linked to permeability contrasts at the Moho. Nat Geosci 5:731-734, doi:10.1038/ngeo1559

Kawano S, Katayama I, Okazaki K (2011) Permeability anisotropy of serpentinite and fluid pathways in a subduction zone. Geology 39:939-942, doi:10.1130/ G32173.1

Kikuchi M, Nakamura M, Yoshikawa K (2003) Source rupture process of the 1944 Tonankai earthquake and the 1945 Mikawa earthquake derived from lowgrain seismograms. Earth Planets Space 55:159-172

Kimura G, Yamaguchi A, Hojo M, Kitamura Y, Kameda J, Ujiie K, Hamada Y, Hamahashi M, Hina S (2012) Tectonic mélange as fault rock of subduction plate boundary. Tectonophysics 568-569:25-38, doi:10.1016/j. tecto.2011.08.025

Kimura G, Hamahashi M, Okamoto S, Yamaguchi A, Kameda J, Raimbourg H, Hamada Y, Yamaguchi H, Shibata T (2013) Hanging wall deformation of a seismogenic megasplay fault in an accretionary prism: the Nobeoka Thrust in southwest Japan. J Struct Geol 52:136-147

Kinoshita M, Tobin H, Ashi J, Kimura G, Lallemant S, Screaton EJ, Curewitz D, Masago H, Moe KT (2009) the Expedition 314/315/316 Scientists (2009) 
Proceedings of the Integrated Ocean Drilling Program, Volume 314/315/ 316th edn. Integrated Ocean Drilling Program Management International, Inc, Washington, D.C, doi:10.2204/iodp.proc.314315316.133.2009

Kirkpatrick JD, Dobson K, Mark DF, Shipton ZK, Brodsky EE, Stuart FM (2012) The depth of pseudotachylyte formation from detailed thermochronology and constraints on coseismic stress drop variability. J Geophys Res doi:10.1029/ 2011JB008846

Kirkpatrick JD, Rowe CD (2013) Disappearing ink: how pseudotachylytes are lost from the rock record. J Struct Geol 52:183-198, doi:10.1016/j.jsg.2013.03.003

Kitajima H, Chester JS, Chester FM, Shimamoto T (2010) High-speed friction of disaggregated ultracataclasite in rotary shear: characterization of frictional heating, mechanical behavior, and microstructure evolution. J Geophys Res doi:10.1029/2009JB007038

Kitajima H, Saffer DM (2012) Elevated pore pressure and anomalously low stress in regions of low frequency earthquakes along the Nankai Trough subduction megathrust. Geophys Res Lett doi:10.1029/2012GL053793

Kitamura Y, Sato K, Ikesawa E, Ikehara-Ohmori K, Kimura G, Kondo H, Ujiie K, Onishi CT, Kawabata K, Hashimoto Y, Mukoyoshi H, Masago H (2005) Mélange and its seismogenic roof décollement: a plate boundary fault rock in the subduction zone-an example from the Shimanto Belt, Japan. Tectonics doi:10.1029/2004TC001635

Kitamura M, Mukoyoshi H, Fulton PM, Hirose T (2012) Coal maturation by frictional heat during rapid fault slip. Geophys Res Lett doi:10.1029/ 2012GL052316

Kitano T, Kataoka T, Shirota T (1981) An empirical equation of the relative viscosity of polymer melts filled with various inorganic fillers. Rheol Acta 20:207-209

Kodaira S, No T, Nakamura Y, Fujiwara T, Kaiho Y, Miura S, Takahashi N, Kaneda Y, Taira A (2012) Coseismic fault rupture at the trench axis during the 2011 Tohoku-oki earthquake. Nat Geosci 5:646-650, doi:10.1038/ngeo1547

Kondo H, Kimura G, Masago H, Ikehara-Ohmori K, Kitamura Y, Ikesawa E, Sakaguchi A, Yamaguchi A, Okamoto S (2005) Deformation and fluid flow of a major out-of-sequence thrust located at seismogenic depth in an accretionary complex: Nobeoka Thrust in the Shimano Belt, Kyushu, Japan. Tectonics doi:10.1029/2004TC001655

Lachenbruch AH (1980) Frictional heating, fluid pressure, and the resistance to fault motion. J Geophys Res 85:6097-6112

Lejeune A-M, Richet P (1995) Rheology of crystal-bearing silicate melts: an experimental study at high viscosities. J Geophys Res 100:4215-4229, doi:10.1029/94JB02985

Lofgren G (1980) Experimental studies on the dynamic crystallization of silicate melts. In: Hargraves RB (ed) Physics of magmatic processes. Princeton University Press, Princeton, New Jersey, pp 487-551

Ma K-F, Tanaka H, Song S-R, Wang C-Y, Hung J-H, Tsai T-B, Mori J, Song Y-F, Yeh E-C, Soh W, Sone H, Kuo L-W, Wu H-Y (2006) Slip zone and energetics of a large earthquake from the Taiwan Chelungpu-fault Drilling Project. Nature 444:473-476, doi:10.1038/nature05253

Maddock RH (1992) Effects of lithology, cataclasis and melting on the composition of fault-generated pseudotachylytes in Lewisian gneiss, Scotland. Tectonophysics 204:261-278

Magloughlin JF (1992) Microstructural and chemical changes associated with cataclasis and frictional melting at shallow crustal levels: the cataclasitepseudotachylyte connection. Tectonophysics 204:243-260

Magloughlin JF, Spray JG (1992) Frictional melting processes and products in geological materials: introduction and discussion. Tectonophysics 204:197-206

Marone C, Scholz CH (1988) The depth of seismic faulting and the upper transition from stable to unstable slip regimes. Geophys Res Lett 15:621-624

Mase CW, Smith L (1987) Effects of frictional heating on the thermal, hydrologic, and mechanical response of a fault. J Geophys Res 92:6249-6272

Matsubara M, Obara K, Kasahara K (2009) High-V $V_{p} / V_{s}$ zone accompanying non-volcanic tremors and slow-slip events beneath southwestern Japan. Tectonophysics 472:6-17, doi:10.1016/j.tecto.2008.06.013

McConville CJ, Lee WE (2005) Microstructural development on firing illite and smectite clays compared with that in kaolinite. J Am Ceram Soc 88:2267-2276

Melosh HJ (1996) Dynamic weakening of faults by acoustic fluidization. Nature 379:601-606

Metzner AB (1985) Rheology of suspensions in polymeric liquids. J Rheol 29:739-775

Meneghini F, Moore JC (2007) Deformation and hydrofracture in a subduction thrust at seismogenic depths: the Rodeo Cove thrust zone, Marine Headlands, California. Bull Geol Soc Am 119:174-183, doi:10.1130/B25807.1
Meneghini F, Di Toro G, Rowe CD, Moore JC, Tsutsumi A, Yamaguchi A (2010) Record of mega-earthquakes in subduction thrusts: the black fault rocks of Pasagshak Point (Kodiak Island, Alaska). Bull Geol Soc Am 122:1280-1297, doi:10.1130/B30049.1

Mizoguchi K, Hirose T, Shimamoto T, Fukuyama E (2009) High-velocity frictional behavior and microstructure evolution of fault gouge obtained from Nojima fault, southwest Japan. Tectonophysics 471:285-296, doi:10.1016/j. tecto.2009.02.033

Moecher DP, Brearley AJ (2004) Mineralogy and petrology of a mullite-bearing pseudotachylyte: constraints on the temperature of coseismic frictional fusion. Am Min 89:1486-1495

Monzawa N, Otsuki K (2003) Comminution and fluidization of granular fault materials: implications for fault slip behavior. Tectonophysics 367:127-143, doi:10.1016/S0040-1951(03)00133-1

Moore DE, Summers R, Byerlee JD (1989) Sliding behavior and deformation textures of heated illite gouge. J Struct Geol 11:329-342

Moore JC, Saffer D (2001) Updip limit of the seismogenic zone beneath the accretionary prism of southwest Japan: an effect of diagenetic to low-grade metamorphic processes and increasing effective stress. Geology 29:183-186

Moore GF, Park J-O, Bangs NL, Gulick SP, Tobin HJ, Nakamura Y, Sato S, Tsuji T, Yoro T, Tanaka H, Uraki S, Kido Y, Sanada Y, Kuramoto S, Taira A (2009) Structural and seismic stratigraphic framework of the NanTroSEIZE stage 1 transect. In: Proceedings of the Integrated Ocean Drilling Program, Volume 314/315/316th edn. Integrated Ocean Drilling Program Management International, Inc, Washington, D.C, doi:10.2204/iodp.proc.314315316.133.2009

Mukoyoshi H, Sakaguchi A, Otsuki K, Hirono T, Soh W (2006) Co-seismic frictional melting along an out-of-sequence thrust in the Shimanto accretionary complex. Implications on the tsunamigenic potential of splay faults in modern subduction zones. Earth Planet Sci Lett 245:330-343, doi:10.1016/j. epsl.2006.02.039

Mueller S, Llewellin EW, Mader HM (2010) The rheology of suspensions of solid particles. Proc R Soc A 466:1201-1228, 10.1098/rspa.2009.0445

Nielsen S, Di Toro G, Hirose T, Shimamoto T (2008) Frictional melt and seismic slip. J Geophys Res doi:10.1029/2007JB005122

Niemeijer A, Di Toro G, Griffith WA, Bistacchi A, Smith SAF, Nielsen S (2012) Inferring earthquake physics and chemistry using an integrated field and laboratory approach. J Struct Geol 39:2-36, doi:10.1016/j.jsg.2012.02.018

Noda H, Lapusta N (2013) Stable creeping fault segments can become destructive as a result of dynamic weakening. Nature 493:518-523, doi:10.1038/nature11703

Obara K (2002) Nonvolcanic deep tremor associated with subduction in southwest Japan. Science 296:1679-1681

O'Hara K, Mizoguchi K, Shimamoto T, Hower JC (2006) Experimental frictional heating of coal gouge at seismic slip rates: evidence for devolatilization and thermal pressurization of gouge fluids. Tectonophysics 424:109-118, doi:10.1016/j.tecto.2006.07.007

Okamoto S, Kimura G, Takizawa S, Yamaguchi H (2006) Earthquake fault rock indicating a coupled lubrication mechanism. E-earth 1:23-28

Oleskevich DA, Hyndman RD, Wang K (1999) The updip and downdip limits to great subduction earthquakes: thermal and structural models of Cascadia, south Alaska, SW Japan, and Chile. J Geophys Res 104:14965-14991

Otsuki K, Monzawa N, Nagase T (2003) Fluidization and melting of fault gouge during seismic slip: identification in the Nojima fault zone and implications for focal earthquake mechanisms. J Geophys Res doi:10.1029/2001JB001711

Rice JR (2006) Heating and weakening of faults during earthquake slip. J Geophys Res doi:10.1029/2005JB004006

Roedder E (1984) Fluid inclusions. Mineralogical Society of America Reviews in Mineralogy 12:644

Rogers GC, Dragert H (2003) Episodic tremor and slip on the Cascadia subduction zone: the chatter of silent slip. Science 300:1942-1943

Rosato A, Strandburg KJ, Prinz F, Swendsen (1987) Why the Brazil nuts are on top: size segregation of particulate matter by shaking. Phys Rev Lett 58:1038-1040, doi:10.1103/PhysRevLett.58.1038

Rowe CD, Moore JC, Meneghini F, McKeirnan AW (2005) Large-scale pseudotachylytes and fluidized cataclasites from an ancient subduction thrust fault. Geology 33:937-940, doi:10.1130/G21856.1

Rowe CD, Moore JC, Remitti F (2013) the IODP Expedition 343/343T Scientists (2013) The thickness of subduction plate boundary faults from the seafloor into the seismogenic zone. Geology 41:991-994, doi:10.1130/G34556.1

Rudnicki JW, Chen C-H (1988) Stabilization of rapid frictional slip on a weakening fault by dilatant hardening. J Geophys Res 93:4745-4757 
Saffer DM, Marone C (2003) Comparison of smectite- and illite-rich gouge frictional properties: application to the updip limit of the seismogenic zone along subduction megathrusts. Earth Planet Sci Lett 215:219-235, doi:10.1016/S0012-821X(03)00424-2

Saito T, Ujiie K, Tsutsumi A, Kameda J, Shibazaki B (2013) Geological and frictional aspects of very-low-frequency earthquakes in an accretionary prism. Geophys Res Lett 40:703-708, 10.1002/grl.50175

Sakaguchi A, Chester F, Curewitz D, Fabbri O, Goldsby D, Kimura G, Li C-F, Masaki Y, Screaton EJ, Tsutsumi A, Ujiie K, Yamaguchi A (2011) Seismic slip propagation to the updip end of plate boundary subduction interface faults: vitrinite reflectance geothermometry on Integrated Ocean Drilling Program NanTroSEIZE cores. Geology 39:395-398, doi:10.1130/G31642.1

Sato M, Ishikawa T, Ujihara N, Yoshida S, Fujita M, Mochizuki M, Asada A (2011) Displacement above the hypocenter of the 2011 Tohoku-Oki earthquake. Science 332:1395, doi:10.1126/science.107401

Schwartz SY, Rokosky JM (2007) Slow slip events and seismic tremor at circum-pacific subduction zones. Rev Geophys doi:10.1029/2006RG000208

Segall P, Rice J (1995) Dilatancy, compaction, and slip instability of a fluidinfiltrated fault. J Geophys Res 100:22155-22171

Shaw HR (1972) Viscosities of magmatic silicate liquids: an empirical method of prediction. Am J Sci 272:870-893

Shelly DR, Beroza GC, Ide S, Nakamura S (2006) Low-frequency earthquakes in Shikoku, Japan, and their relationship to episodic tremor and slip. Nature 442:188-191

Shibazaki B, Matsuzawa T, Tsutsumi A, Ujiie K, Hasegawa A, Ito Y (2011) 3D modeling of the cycle of a great Tohoku-oki earthquake, considering frictional behavior at low to high slip velocities. Geophys Res Lett doi:10.1029/2011GL049308

Sibson RH (1973) Interactions between temperature and pore-fluid pressure during earthquake faulting and a mechanism for partial or total stress relief. Nat Phys Sci 243:66-68

Sibson RH (1975) Generation of pseudotachylyte by ancient seismic faulting. Geophys J R Astron Soc 43:775-794

Sibson RH (1986) Brecciation processes in fault zones: inferences from earthquake rupturing. Pure Appl Geophys 124:159-175

Sibson RH (1989) Earthquake faulting as a structural process. J Struct Geol 11:1-14

Sibson RH (2003) Thickness of the seismic slip zone. Bull Seismol Soc Am 93:1169-1178, doi:10.1785/0120020061

Sibson RH, Toy VG (2006) The habitat of fault-generated pseudotachylyte: presence vs. absence of friction-melt. In: Abercrombie R (ed) Radiated energy and the physics of earthquake faulting, vol, 170th edn. Geophys Monogr Ser. AGU, Washington DC, pp 153-166

Smith SAF, Collettini C, Holdsworth RE (2008) Recognizing the seismic cycle along ancient faults: $\mathrm{CO}_{2}$-induced fluidization of breccias in the footwall of a sealing low-angle normal fault. J Struct Geol 30:1034-1046, doi:10.1016/j. jsg.2008.04.010

Smith SAF, Billi A, Di Toro G, Spiess R (2011) Principal slip zones in limestone: microstructural characterization and implications for the seismic cycle (Tre Monti fault, central Apennines, Italy). Pure Appl Geophys 168:2365-2393

Spray JG (1992) A physical basis for the frictional melting of some rock-forming minerals. Tectonophysics 204:205-221

Spray JG (1993) Viscosity determinations of some frictionally generated silicate melts: implications for fault zone rheology at high strain rates. J Geophys Res 98:8053-8068

Sugioka H, Okamoto T, Nakamura T, Ishihara Y, Ito A, Obana K, Kinoshita M, Nakahigashi K, Shinohara M, Fukao Y (2012) Tsunamigenic potential of the shallow subduction plate boundary inferred from slow seismic slip. Nat Geosci 5:414-418, doi:10.1038/ngeo1466

Sweeney JJ, Burnham AK (1990) Evaluation of a simple model of vitrinite reflectance based on chemical kinetics. Am Assoc Pet Geol Bull 74:1559-1570

Tanikawa W, Mukoyoshi H, Tadai O, Hirose T, Tsutsumi A, Lin W (2012) Velocity dependence of shear-induced permeability associated with frictional behavior in fault zones of the Nankai subduction zone. J Geophys Res doi:10.1029/ $2011 \mathrm{JB} 008956$

Tanioka Y, Satake K (2001) Detailed coseismic slip distribution of the 1944 Tonankai earthquake estimated from tsunami waveforms. Geophys Res Lett doi:10.1029/2000GL012284

Tobin HJ, Kinoshita M (2006) NanTroSEIZE: the IODP Nankai Trough Seismogenic Zone Experiment. Sci Drill 2:23-27, doi:10.2204/iodp.sd.2.06.2006
Tsutsumi A, Shimamoto T (1997) High-velocity frictional properties of gabbro. Geophys Res Lett 24:699-702

Ujiie K (1997) Off-scraping accretionary process under the subduction of young oceanic crust: the Shimanto Belt of Okinawa Island, Ryukyu Arc. Tectonics 16:305-322

Ujiie K, Yamaguchi A, Kimura G, Toh S (2007a) Fluidization of granular material in a subduction thrust at seismogenic depths. Earth Planet Sci Lett 259:307-318, doi:10.1016/j.epsl.2007.04.049

Ujiie K, Yamaguchi H, Sakaguchi A, Toh S (2007b) Pseudotachylytes in an ancient accretionary complex and implications for melt lubrication during subduction zone earthquakes. J Struct Geol 29:599-613, doi:10.1016/j. jsg.2006.10.012

Ujiie K, Yamaguchi A, Taguchi S (2008) Stretching of fluid inclusions in calcite as an indicator of frictional heating on faults. Geology 36:111-114, doi:10.1130/ G24263A.1

Ujiie K, Tsutsumi A, Fialko Y, Yamaguchi H (2009) Experimental investigation of frictional melting of argillite at high slip rates: implications for seismic slip in subduction-accretion complexes. J Geophys Res doi:10.1029/2008JB006165

Ujiie K, Tsutsumi A (2010) High-velocity frictional properties of clay-rich fault gouge in a megasplay fault zone, Nankai subduction zone. Geophys Res Lett doi:10.1029/2010GL046002

Ujiie K, Tanaka H, Saito T, Tsutsumi A, Mori JJ, Kameda J, Brodsky EE, Chester FM, Eguchi N, Toczko S, Expedition 343 and 343T Scientists (2013) Low coseismic shear stress on the Tohoku-Oki megathrust determined from laboratory experiments. Science 342:1211-1214, doi:10.1126/science.1243485

Vrolijk P, Myers G, Moore JC (1988) Warm fluid migration along tectonic mélanges in the Kodiak accretionary complex, Alaska. J Geophys Res 93:10313-10324

Vrolijk P (1990) On the mechanical role of smectite in subduction zones. Geology 18:703-707

Wells DL, Coppersmith KJ (1994) New empirical relationships among magnitude, rupture length, rupture width, rupture area, and surface displacement. Bull Seismol Soc Am 84:974-1002

Yamaguchi A, Cox SF, Kimura G, Okamoto S (2011a) Dynamic changes in fluid redox state associated with episodic fault rupture along a megasplay fault in a subduction zone. Earth Planet Sci Lett 302:369-377, doi:10.1016/j. epsl.2010.12.029

Yamaguchi A, Sakaguchi A, Sakamoto T, lijima K, Kameda J, Kimura G, Ujiie K, Chester FM, Fabbri O, Goldsby D, Tsutsumi A, Li C-F, Curewitz D (201 lb) Progressive illitization in fault gouge caused by seismic slip propagation along a megasplay fault in the Nankai Trough. Geology 39:995-998, doi:10.1130/G32038

Yamaguchi A, Ujiie K, Nakai S, Kimura G (2012) Sources and physicochemical characteristics of fluids along a subduction-zone megathrust: a geochemical approach using syn-tectonic mineral veins in the Mugi mélange, Shimanto accretionary complex. Geochem Geophys Geosyst doi:10.1029/ $2012 \mathrm{GC} 004137$

Yan Y, van der Pluijm B, Peacor D (2001) Deformational microfabrics of clay gouge, Lewis Thrust, Canada: a case for fault weakening from clay transformation. In: Holdsworth RE, Strachan RA, Magloughlin JF, Knipe RJ (eds). The nature and tectonic significance of fault zone weakening, vol 186, Geological Society, London, Special Publication, pp 103-112

doi:10.1186/2197-4284-1-7

Cite this article as: Ujiie and Kimura: Earthquake faulting in subduction zones: insights from fault rocks in accretionary prisms. Progress in Earth and Planetary Science 2014 1:7. 